\title{
El tiempo de la archivística: un estudio de sus espacios de racionalidad histórica*
}

\begin{abstract}
Agustín Vivas Moreno
Doctor em documentación, licenciado em historia moderna, profesor titular de Universidad, área de biblioteconomía y documentación, Facultad de Documentación, Universidad de Extremadura, Facultad de Biblioteconomía y Documentación Universidad de Extremadura. E-mail: avivas@alcazaba.unex.es
\end{abstract}

\section{Resumen \\ Nuestra propuesta tiene como objetivo principal la confección de las bases que conformen una Historia Cultural de la Archivistica. Para ello, nos basamos en un eje fundamental: la formulación de los diferentes "espacios de racionalidad histórica" que han conformado la historia de la disciplina. Dicho esto,entendemos por espacio de racionalidad aquella combinación determinada y bien caracterizada de factores que conforman un sistema en función de una cierta homogeneidad histórica y cuyo modelo puede ser establecido. De este modo,concebimos que en el desarrollo archivistico hay cuatro grandes espacios de racionalidad histórica: la archivística como instrumento inductivo y funcional, la archivística como doctrina patrimonial y jurídico- administrativa, la archivística como desarrollo historiográfico y teoría especulativa y la archivística en la sociedad del conocimiento. Cuyas peculiaridades podrían quedar especificadas a través de la ampliación del campo de actuación de la archivística, su expansión científica, su inserción en el ámbito de las Ciencias de la Documentación, la determinación de los archivos como sistemas de información, y el determinismo tecnológico. En el desarrollo metodológico de nuestra propuesta precisamos la interacción que produce diferentes factores socio-culturales, que han sabido articular en su devenir histórico la configuración de los diferentes espacios de inteligibilidad de la historia de la archivística. De todo ello, inferimos como resultado principal que dichos espacios de inteligibilidad son básicos para la comprensión de la historia cultural de la archivistica, concepto innovador. \\ Palabras clave \\ Factores socio-culturales; Historia cultural; Historia de la archivística; Periodización histórica.}

\section{Time of archival science - a review of its historic rationality spaces}

\section{Abstract}

The main objective of this proposal is to build up baselines for a Cultural History of Archival Science. For this purpose, it is based on a seminal axis: the formulation of several "historic rationality spaces" which have conformed the history of the field. It can be said that a rationality space is a well determined and characterized combination of forces which conform a system based on some historic homogeneity and whose model can be established. So, the conception is that there are four great historic rationality spaces in archival development: Archival science as an inductive and functional instrument, Archival science as patrimonial and legal-administrative field, Archival science as a historiographic development and speculative theory, and Archival science in knowledge society. Its vagaries would be specified through the extension of archival science scope, its scientific expansion, its insertion in Information Science field, determination of archives as information systems, and technological determinism. In methodological development of our proposal, it is specified the interoperation among several sociocultural forces, which have formed, in their historic course, the different understanding archival science history spaces. In consequence, we infer as a main result that understanding spaces are basic for comprehension of archival science cultural history, a ground-breaking concept.

\section{Keywords}

Sociocultural forces; Cultural history; Archival

science history; Historic schedule setting.

\footnotetext{
* Nota: Tratando-se de artigo de revisão, excepcionalmente a editoria da revista manteve as notas de rodapé conforme foram apresentadas pelo autor.
}

\section{INTRODUCCIÓN}

El propósito de esta trabajo, dado su carácter genérico e introductorio es, ciertamente, complejo: reconstruir de manera simplificada la historia de la Archivística, e intentar vislumbrar el proceso evolutivo de la disciplina ${ }^{1}$ que discurre "de práctica a ciencia", de "período prearchivístico" a "período de desarrollo archivístico", de "práctica a teoría científica".

Se trata, por consiguiente, de un estudio de explícita interdiciplinariedad: la Archivística empírica y científica, el estudio de las Reformas Administrativas con sus continuas modificaciones, y el contexto histórico, componen, de forma conjunta, las líneas evolutivas sobre las que metodológicamente he fundamentado el presente análisis. En consecuencia, y basándome precisamente en el concepto de archivo, observaremos, tal y como explica Rodríguez de Diego, como todo cambio de procedimiento documental debe ser asociado a una reforma administrativa y éstas, a su vez, derivan de unas coordenadas espacio-temporales que las explican y justifican. ${ }^{5}$

Ciertamente no han sido pocos los problemas que subyacen en un trabajo que tiene por objeto el estudio de la historia de la archivística, y que deben quedar necesariamente

${ }^{1}$ BUCCI, O. "Il processo evolutivo dell'archivistica e il suo insegnamento nell'Università di Macerata". En Actas dela Conferenza Internazionale: L'Archivistica alle soglie del 2000. Macerata: Universitá, 1992, pp. 18-22; D'ADDARIO, A. "Lineamenti di storia dell'archivistica (secc. XVIXX)". Archivio Storico Italiano. 1990, Anno 148, pp. 3-35; LODOLINI, E. Lineamenti di storia dell'archivística italiana. Dalle origini alla metà del secolo XX. Roma: La Nuova Italia Scientifica, 1991.

${ }^{2}$ MENDO CARMONA, C. "El largo camino de la Archivística: de práctica a ciencia" . SIGNO. Revista de Historia de la Cultura Escrita. 1995, № 2, pp. 113-132; ídem "Los Archivos y la Archivística: evolución histórica y actualidad”. En RUIZ RODRÍGUEZ, A.A. (Ed.) Manual de Archivística. Madrid: Síntesis, 1995, pp. 19-36.

${ }^{3}$ CRUZ MUNDET, J.R. Manual de Archivística. Madrid: Fundación Germán Sánchez Ruipérez: Pirámide, 1994, pp. 26-54.

${ }^{4}$ LÓPEZ GÓMEZ, P. "La tradición archivística española”. Boletín Informativo. Instituto Andaluz del Patrimonio Histórico. 1995, Vol. III, № 12, pp. 66-70; y "La Archivística en la formación profesional". En Actas del I Congresso Nacional de Bibliotecários, Arquivistas e Documentalistas: A Informaçao em Tempo de Mudaça. Oporto: BAD, 1985, vol. I, pp. 425-443.

${ }^{5}$ RODRÍGUEZ DE DIEGO, J.L. "Archivos del Poder, archivos de la administración, archivos de la Historia". En GENERELO, J.J. y MORENO LÓPEZ, Á. (Coords.). Historia de los Archivos y de la Archivística en España. Valladolid: Universidad de Valladolid, 1998, pp. 29-42; idem. "Archivos de la Administración Central desde el s. XV al s. XX". Irargi. Revista de Archivística. Vol. II, 1989, pp. 37-102. 
explicitados cuanto antes. El primero de ellos se deriva de la ausencia de trabajos de síntesis previos de investigación y de la extraordinaria dispersión historiográfica, lo cual trae consigo resultados bibliográficos desiguales y fragmentarios. En este sentido, y al margen de pocas contribuciones que más adelante quedarán convenientemente citadas, serían muy deseables estudios que sistematizaran y pusieran orden a los acuerdos según el estado actual de nuestros conocimientos, que si bien es cierto que dista mucho de ser íntegro, permite a nuestro juicio conciertos consolidados.

El segundo deviene del mencionado carácter multidisciplinario del contenido, debido en parte a la peculiar condición multíplice que subyace en la disciplina archivística. La Historia, la Archivística, la Diplomática, la Historia del Derecho y de la Administración Pública, las Ciencias Documentales o las Tecnologías de la Información son, entre otras, disciplinas que encuentran perfecto acuerdo y compostura en una investigación como la que nos proponemos conducir. De este modo, en determinadas ocasiones, las conexiones que se producen entre ellas son ciertamente claras pero de difícil resolución para un contenido que pretende ser de síntesis, lo cuál nos obliga en no pocas veces a simplificar de forma imprecisa la realidad circundante. El tercer problema tiene su fundamento en la aplicación de la metodología empleada para análisis de largo tiempo. En este orden de cosas, con la exposición constataremos cómo determinados factores socio-culturales que, según nuestra opinión, han contribuido al desarrollo de la disciplina archivística, lo hacen, en determinadas ocasiones, no de forma uniforme y progresiva, sino de manera discontinua y poco persistente - es evidente, por ejemplo, el desmantelamiento documental y archivístico de la Alta Edad Media, frente al florecimiento que tuvo lugar con la cultura greco-romana. En definitiva, en un largo espacio de tiempo las estructuras varían en virtud de múltiples contingencias, dificultando en gran medida la exigencia de estabilidad y perdurabilidad en el tiempo que debe cumplir todo hipotético modelo teórico, máxime cuando pretende adaptarse a los diferentes sistemas socioculturales.

Aclarado esto, es es necesario dilucidar ya, que nuestro principal objetivo ha consistido en especificar cuáles han sido los períodos más significativos de la historia de la disciplina archivística y cuáles las características más notorias que acaban determinando la existencia y particularidad de los mismos. Para ello, nos alejaremos del empirismo positivista que entraña el estudio analítico de la historia de las diferentes prácticas de gobierno, de sus consecuentes prácticas documentales y de los diferentes archivos que irán surgiendo como consecuencia de aquéllas, y nos emplearemos en el ejercicio deductivo que se infiere de todo lo anterior, ofreciendo un resultado de matices más genéricos y globales. Convenimos en pensar, por tanto, que la historia de la archivística no sólo es el estudio de la génesis documental fundamentado en un complicado desarrollo jurídico o el análisis del paulatino despliegue teórico de los principios científicos que mediante su formulación, debate, aplicación práctica y universalización cimentaron las bases de la teoría archivística moderna. Estamos, en definitiva, ante la praxis política de los diferentes métodos administrativos - conformado en gran medida por el peso que han supuesto las tradiciones administrativas fruto de dilatadas aptitudes culturales y de los usos practicados desde el poder establecido -, del ejercicio de toma de decisiones y el consecuente despliegue del poder, y del uso vehemente que de los archivos y documentos se operan, ya sea para la propia administración, para la historia, o como procedimiento de dominio y control.

Llegados a este punto, y desde una perspectiva meramente indicativa y sin incurrir en un complejo entramado de títulos y nombres, veamos a modo de grandes trazos, las carencias y limitaciones en lo concerniente a la literaturaque investiga el tiempo de la archivística.

Cabe comenzar afirmando que la historia de los archivos y de la archivística es una de las líneas de investigación o categoría temática que cualquier clasificación convencional sobre temas de investigación en Archivística distingue. ${ }^{6}$ En este sentido, es un hecho constatable su incremento durante los años 90, lo cual parece indicar un afán por buscar los orígenes de la Archivístca como saber científico consolidado. Dicho esto, a pesar del desarrollo de los últimos años, son notorias algunas de las carencias con las que nos hemos topado a la hora de realizar este análisis:

'Vid. por orden cronológico: MUÑOZ GUTIÉRREZ, C. "The state of research in archival science”. Archivum. 1994, vol. 39, págs. 530-532 (distingue entre principios y conceptos por un lado e Historia de los Archivos y de la Archivística por otro); PEDERSON, A.E. "Development of research programs”. Archivum. 1994, vol. 39, págs. 312-359 (distingue entre Naturaleza de la información y de los documentos, gestión de programas y de servicios de archivos, funciones archivísticas, problemas de carácter archivística - ética, tecnologías, etc. - e Historia social e institucional de los archivos); CRAIG, B.L. "Serving the truth: the importante of fostering archives research in education programmes, including a modest proposal for partnerships with the workplace”. Archivaria. 1996, № 42, págs. 105-117 (distingue entree funciones archivísticas, tecnologías aplicadas e Historia de la Archivística); y COUTURE, C. y DUCHARME, D. "La recherche en archivistique: un état de la question”. Archives. 1998-1999, vol. 30, № 3-4, págs. 11-37 (la clasificación más completa, que distingue entre objeto y finalidad de la archivística, archivos y sociedad, gestión de programas y de servicios de archivos, funciones archivísticas, tecnologías aplicadas, soportes y tipos de archivos, problemas particulares e Historia de los archivos y de la archivística).Se incluyen en esta categoría temática todo lo relativo a la historia de los archivos y de los organismos archivísticos, de los documentos, de las instituciones productoras documentales, y de los aspectos teóricos relacionados con la archivística, estudiados, todos ello, exclusivamente desde una perspectiva histórica. Se engloban algunos estudios de carácter no específicamente archivístico, sino diplomático, paleográfico o relativos al patrimonio documental como fuente para la investigación histórica. 


\section{Agustín Vivas Moreno}

1. Falta de obras generales interdisciplinares y estudios sintéticos. Ya lo hemos dicho. Su ausencia se debe en gran medida a la necesidad de equipos interdisciplinares con investigadores altamente especializados para cada una de las etapas históricas. Sería deseable, pues, una historia global, sintética y condensada de la historia de los archivos y de la archivística, más allá de un número limitado de ponencias yuxtapuestas, con contenidos en unos casos repetitivos y en otros ausentes.

\section{Falta de obras que interrelacionen la historia de los archivos} y de la archivística con su contexto histórico. Son muy pocas, y en la mayoría de los casos de forma breve e incluidas en obras de historia o diplomática, las páginas que explican las características de desarrollo archivístico en su contexto histórico y administrativo. Se echan en falta estudios que analicen cómo cada estructura administrativa conforma sus propios archivos con características documentales, con peculiaridades organizativas propias, y hasta con distintos ámbitos de actuación. En definitiva, son deseables investigaciones que analicen la interdependencia entre procesos socio-políticos y archivística. El factor social, pues, como elemento imprescindible para explicar la realidad archivística.

3. Falta de repertorios de fuentes. Este tipo de publicaciones son de gran utilidad por lo valiosas y útiles que resultan a la hora de concebir cualquier trabajo, máxime cuando son muy numerosos los análisis localistas y los estudios parciales sobre la historia de determinados fondos de archivo. Faltan, en este sentido, repertorios bibliográficos exhaustivos, e incluso unos Cuadernos Bibliográficos de Historia de los Archivos y de la Archivística, que permitieran la recuperación de la información mediante, nombres, lugares, entidades o materias.

4. Falta de ediciones de texto. Es, sin duda alguna, uno de los sectores más fundamentales, aunque desafortunadamente menos elaborado de la bibliografía del último medio siglo. Baste decir que no contamos con ediciones de textos que considero fundamentales para la Historia de los Archivos, tales como ordenanzas medievales o modernas, o los numerosos informes científicos que se mandaban realizar en el s. XIX cuando el rigor tecnicista y cientificista se imponía?

5. Falta de determinados estudios monográficos. Evidentemente no todo está investigado, sino que

\footnotetext{
${ }^{7}$ Nosotros acabamos de sacar a la luz uno de esos documentos que consideramos de enorme interés. VIVAS MORENO, A. Lecturas y documentos históricos en Archivos: Un informe del s. XIX para la organización del Archivo de la Universidad de Salamanca. Badajoz: Universidad de Extremadura, 2001.
}

faltan abundantes cuestiones que necesitan de estudios concretos y exhaustivos. Es el caso de determinados aspectos vinculados a la documentación de la época moderna, a aspectos históricos de instituciones de notable relieve, a determinados análisis de procedencias de fondos documentales, o a trabajos que analizaran el personal científico y técnico de los archivos que durante largo tiempo se ha responsabilizado del cuidado de los documentos. Bien es cierto que constatamos un gran avance en los últimos años, habiéndose cubierto análisis sectoriales para la época moderna y contemporánea.

En definitiva, sería necesario contar con una coordinación institucional para el tema en cuestión que guiara mediante concierto y ajuste la multiplicidad dispersa de abundantes obras. La amplitud cronológica, la riqueza de los fondos documentales, las numerosas instituciones objeto de estudio o la interrelación consecuente con otras disciplinas favorecen la presencia de un centro documental específico, más allá de los organismos institucionales hoy existentes. Ello evitaría, por un lado, la ingente dispersión bibliográfica existente, constatada en en multitud de colecciones y revistas de diferentes materias (Archivística, Historia, Derecho, Instituciones, etc.), y por otro, la amplitud y complejidad temática motivada por la extraordinaria interdependencia con otras disciplinas.

\section{LA ARTICULACIÓN DE LA ARCHIVÍSTICA EN PERIODOS HISTÓRICOS}

\section{LOS PERIODOS HISTÓRICOS COMO ESPACIOS DE RACIONALIDAD HISTÓRICA}

Antes de adentrarnos en el tema, hemos de aclarar que entendemos que los intentos por esclarecer periodizaciones son un método de análisis del proceso histórico de una época o una disciplina. Mediante ello se intenta revelar cuáles son las circunstancias y procesos críticos de una etapa, sus condiciones y referencias sustanciales, en definitiva, cuáles las rupturas y cuáles las continuidades que se suponen estructurales. No es pues el asunto que nos depara un mero recurso pedagógico. Por mucho que el Ser y el Devenir históricos se resistan a que, como forma de análisis, se les quebrante en períodos, épocas o partes, las diferentes periodizaciones surgen sólo como condicionales de la necesidad científica de entrever el ininterrumpido encadenamiento de los acontecimientos y del conocimiento más profundizado de las relaciones del devenir histórico.

Con todo, no es este el momento de argumentar acerca del concepto de período histórico, dado que ello supondría, entre otras cuestiones, comentar el significado de la 
dimensión del Tiempo en la Historia, la controversia continuidad/ruptura en el devenir histórico, las diferentes teorías al efecto (linealidad histórica, teoría de los ciclos históricos, el estacionamiento histórico), los tipos de cambios que se suceden en orden a los diferentes modelos de representación, etc. lo cual nos alejaría en mucho lo que nos ahora nos concierne. ${ }^{8}$ Sin embargo, no nos resistimos a hacer nuestra la opinión de Bauer, según la cual, para una buena periodización deben regir al menos tres principios que hemos intentado respetar en nuestro análisis:

1. Cada período debe ser deducido de su objeto, esto es, basado en los hechos históricos mismos o en el contexto y circunstancias que abarca, no utilizando concepciones presentistas en el juicio y posterior segmentación temporal.

2. Todo período debe reunir unas características propias que le delimiten y configuren, distinguiéndose claramente del que le precede y del que le sucede, sin por ello caer en posiciones rupturistas inapropiadas $\mathrm{y}$, a todas luces, inexactas.

3. Los criterios de análisis para la distinción de los períodos deben ser de naturaleza uniforme, dado que de diferentes criterios es factible distintas periodizaciones complementarias. ${ }^{9}$

En definitiva, entendemos por período histórico aquel lapso de tiempo caracterizado por determinados agentes y factores que configuran con su permanencia una estructura

\footnotetext{
${ }^{8}$ La bibliografía es extensa y rica en matices, dependiendo de escuelas, corrientes y enfoques. La Teoría de la Historia, también en su fértil historiografía, ha tratado el problema del Tiempo en la Historia y su posible segmentación con frecuencia, bien de forma directa o bien de manera colateral. Sin ningún ánimo de exhaustividad y a modo de referencia vid.: ARÓSTEGUI, J. "El análisis de la temporalidad". En: La investigación histórica: teoría y método. Barcelona: Crítica, 1995, pp. 217-230; ARRILLAGA TORRENS, R. "Los períodos históricos". En: Introducción a los problemas de la Historia Madrid; Alianza Editorial, 1982, pp. 184-196; BAUER, G. "La configuración y la división de la materia". En: Introducción al estudio de la Historia. Barcelona: Bosch, 1970, pp. 139. 210; BRAUDEL, F. "Histoire et Sciences Sociales. La longue durée".En: Ecrits sur l'histoire. París: Flammarion, 1969, pp. 41-83; CARRERAS, J.J. "Categorías historiográficas y periodificación histórica". En: CARREAS, J.J. et al. Once ensayos sobre la Historia. Madrid: Fundación Juan March, 1976, pp. XXXX; COLLINGWOOD, R.G. "La teoría de los ciclos históricos". En: Ensayos sobre filosofía de la Historia. Barcelona: Barral, 1970, pp. 119-135; IMBERT, G. Des mouvements de longue durée Kondratieff. Aix en Provence: La pensée Universitaire,1960; KOSELLECK, R. Futuro pasado. Contribución a la semántica de los tiempos históricos. Barcelona. Paidós, 1993, pp. 19 y ss.; MORAZÉ, C. "Las estructuras temporales". En: BASTIDE, R. et al. Sentidos y usos del término estructura en las ciencias del hombre. Buenos Aires: Paidós, 1971, pp. 101 y ss.; VOSS, J. Das Mittelalter im historischem Denken Frankreichs. Munich: Fink Verlag, 1972, etc.

9 BAUER, G. "La configuración y la división de la materia" Op. Cit., pp. 156-157.
}

estable que evoluciona de manera imperceptible, y que se configura como un espacio de inteligibilidad histórica. ${ }^{10}$ Evidentemente, en la medida en que pongamos nuestra observación en un mayor o menor número de factores los períodos serán más dilatados y fluidos, o más lacónicos pero mejor personalizados respectivamente.

\section{VARIADAS ARTICULACIONES DE LA ARCHIVÍSTICA EN PERÍODOS HISTÓRICOS}

Es conveniente dejar claro desde el principio que existe una evidente disparidad entre la disciplina que nos ocupa - la Archivística- y su objeto de atención - los archivos. Si estos últimos tienen una existencia que se remonta a mediados del cuarto milenio a. de C., esto es, cuando tuvieron lugar los primeros orígenes de la escritura con las antiguas civilizaciones ${ }^{11}$, la ciencia y disciplina que se ocupa de ellos es relativamente reciente, dado que surge con la formulación teórica y explícita de sus principios fundamentales, a mediados del s. XIX. De esta forma, el análisis y la investigación de contenidos tan íntimamente vinculados ${ }^{12}$ como la Historia de los Archivos y la Historia de la Archivística se nos presentan con límites periódicos distintos y etapas diferentes. No obstante, intentaremos conjugarlo en las páginas que siguen, dado que se logra entrever un proceso evolutivo de la disciplina que discurre de "práctica a teoría científica". ${ }^{13}$

Para la exposición del desarrollo archivístico no ha existido unanimidad. Dos de los primeros autores que segmentaron la archivística fueron E. Casanova y A. Brenneke. El primero expone una historia de la disciplina fraccionada en cuatro periodos: uno primero hasta el siglo XIII, el segundo para los siglos XIII y XIV, el tercero para los siglos XVI-XVIII, y el cuarto hasta el s. XX. Explica de forma exhaustiva para cada una de las etapas las instituciones archivísticas que surgen, los avances reglamentarios que tienen lugar, el contexto institucional y administrativo,

\footnotetext{
${ }^{10}$ Expresión de J. Aróstegui. Cfr."La periodización en la historiografía: el "espacio de inteligibilidd"” Op. Cit., pp. 225-230.

${ }^{11}$ Cfr. CRUZ MUNDET, J.R. Manual de Archivística. Op. Cit. p. 21; ESCOLAR, H. Historia del libro. Madrid: Fundación Germán Sánchez Ruipérez, 1988, pp. 30-35; GAUR, A. Historia de la escritura. Madrid: Fundación Germán Sánchez Ruipérez, 1988, pp. 69-73.

${ }^{12}$ Vid. al respecto las clásicas obras de BRENNEKE, A. Archivistica. Contributo alla teoria ed alla storia archivistica europea. Milán, 1968; CASANOVA, E. Archiistica. Siena: Lazzeri, 1928; y SANDRI, L. "La storia degli archivi” En Actes du Viéme Congrès International des Archives, publicadas en Archivum, 1968, Vol. XVIII, pp. 102 y ss.

${ }^{13}$ BUCCI, O. "Il processo evolutivo dell'archivistica e il suo insegnamento nell'Università di Macerata". En Actas dela Conferenza Internazionale: L'Archivistica alle soglie del 2000. Macerata: Universitá, 1992, pp. 18-22; D'ADDARIO, A. "Lineamenti di storia dell'archivistica (secc. XVIXX)". Archivio Storico Italiano. 1990, anno 148, pp. 3-35; LODOLINI, E. Lineamenti di storia dell'archivística italiana. Dalle origini alla metà del secolo XX. Roma: La Nuova Italia Scientifica, 1991.
} 
etc., observando, en definitiva, un progresivo desarrollo conceptual ${ }^{14}$.

Por su parte, Adolf Brenneke asignó la segunda parte de su obra a la historia de la archivística y de los archivos. Señaló tres grandes etapas: un primera, que comprendería los siglos XVI y XVII, cuya característica fundamental es el carácter técnico y experimental de la archivística - basado en la obra de Hans Kaiser -; una segunda, centrada en el s. XVIII, cuya propiedad sustancial, dado el contexto racional e ilustrado, sería el sistema de clasificación archivística de carácter deductivo y basado en un corpus teórico confeccionado; y, por último, una tercera época, que se corresponde con el s. XIX, etapa en la que tiene lugar la mayor revolución de la teoría archivística, basada en la consolidación de los principios teóricos como nueva forma de clasificación y organización archivística -que son explicados mediante la disputa ideológica de la teoría archivística prusiana entre H.A. Erhard, L. F. Hoefer y F.L. Von Medem. ${ }^{15}$

Sin embargo, han sido por un lado el francés Robert Henri Bautier, y por otro los italianos Leopoldo Sandri y Elio

${ }^{14}$ CASANOVA, E. Archivística. Siena: Stab. arti grafiche Lazzeeri, 1928. Vid. Cap. III, pp. 291-422.La parte del libro que más nos concierne se encuentra sistematizada de la siguiente manera:

III Storia degli archivi e dell'archivistica

Fonti della storia degli archivi e dell' archivistica

I. Gli archivi e l'archivistica nell'evo antico e sino al sec. XIII. 1 Antichità; 2. Roma; 3. Alto Medio Evo; 4. Notari; 5. Raccolta di atti presso le chiesse; 6. Archivi della Chiesa; 7. Insinuazione degli atti; 8. Archivi normanni; 9. Riforma d'Innocenzo III; 10. Archivi Eclesiasticci; 11. Archivi Viatorii; 12. Cartulari

II. Gli Archivi e l'archivistica nei sec. XIII e XIV. 1. Istrumentari; 2. Comuni; 3. Raccolta degli atti del Comune; 4. Notari Cancellieri; 5. Custodia e conservazione degli atti dei Comuni; 6. Statuti sugli archivi dei Comuni; 7. Mobili; 8. Archivi Svevi; 9. Archivi Angioini; 10. Archivi regi, francesi, inglesi, ec.; 11. Versamenti ed eliminazioni; 12. Decadenza nel sec. XIV; 13. Firenze e altri comuni; 14 . Regolamenti delle regine Sancia e Giovanna I; 15. Inventari; 16. Archivi secreti, archivi generali; 17. Archivi Veneti, inglesi, spagnuoli, ec. Massimiliano I

III. Gli Archivi e l'archivistica nei secoli XVI-XVIII. 1. Cronisti e studiosi; 2. Filippo II; 3. Regolamiento di Filippo III; 4-5. Archivi Pontifici. Rivendicazione. Prelazione 6-7. Archivi ecclesiasticci; 8. Archivi Veneti; 9. Toscana; 10. Concentramenti, Archivio di Vienna; 11. Letteratura archivistica sino a tutto il secolo XVIII; 12. Ordinamento per materie; 13. Le Moine e Chevriéres; 14. Pescarenico e kaunitz. Sistema peroniano; 15. Encliclopedismo e sua influenza sull'archivistica; 16. Cabinet des Chartes; 17. Eliminazioni;

IV Gli archivi e l'Archivistica sino al giorni nostri. 1. Centralizzazione prescritta dalla convenzione; 2. Proposta di centralizzazione della Repubblica Cisalpina; 3. Centralizzazione Napoleonica; 4. Gli archivi nel diritto internazionale. Ricuperi; 5. Ordinamento degli archivi francesi; 6. Metodo storico; 7. Scuole, Ecole de Chartes, ec. Preparazione degli archivisti, insegnamento dell'archivistica, trattatisti; 8. Movimento scientifico; 9. Eccessi. Periodici archivistici; 10. Publicazioni ufficiali; 11. Archivi minori; 12.; 12. Archivi Privati; 13. Difussione degli Archivi, centralizzazione, concentrazione; 14. Stato e amministrazione degli archivi nei vari paesi; 15 . Modificazioni e progressi nell'Archiveconomia; 16. Progressi dell'archivistica.
Lodolini, los que, desde criterios y agentes diferentes, han periodizado la disciplina archivística, tal vez de forma más comprometida y clarividente.

La periodización para la historia de la archivística que establece Bautier ${ }^{16}$ se corresponde en gran medida a la comúnmente seguida, desde un punto de vista global, para la historia en su conjunto; esto es, Edad Antigua, o lo que denomina Archivos de Palacio, Edad Media o Tesoros Documentales (de chartes), Edad Moderna o los Archivos como arsenal de la autoridad, y Edad Contemporánea o Archivos como laboratorios de la Historia. La primera nos acerca a una concepción del archivo eminentemente patrimonial y administrativo, que se establece de forma generalizada durante la segunda etapa. Más tarde, durante los siglos XVI y XVII nacen los archivos de Estado, y surgen de forma gradual cada uno de los principios de la archivística que más tarde acabarán por darle forma. En este momento, los archivos son concebidos como un instrumento puesto a disposición del poder. Por último, los depósitos de los archivos dejan de ser considerados como un arsenal de armas jurídicas y políticas, y pasan a convertirse en laboratorios de investigaciones históricas.

${ }^{15}$ BRENNEKE, A. Archivkunde. Ein Beitrag zur Theorie und Geschichte des europäischen Archivwesens. Leipzig, 1953. Se trata de los apuntes tomados por Wolfgang Leesch de las lecciones impartidas pr A. Brenneke en la Universidad. (Archivistica. Contributo alla teoria ed alla storia archivistica europea. Op. Cit.).La parte del libro que más nos interesa se encuentra estructurada de la siguiente forma:

II. Lineamenti di una storia generale degli archivi

CAPITOLO VII: Gli archivi antichi e medievali (dualismo fra archivio di spedizione ed archivio di ricezione).1. Gli Archivi antichi; 2. Gli archivi pontifici; 3. Gli Archivi della Germania antica (fino al 1806);4. Gli Archivi ecclesiastici; 5. Gli Archivi delle città; 6. Gli Archivi dinastici (archivi delle dinastie che ebbero sovranità territoriale o che furono membri dell'alta aristocrazia)

CAPITOLO VIII: I Grandi Archivi degli Stati regionali tedeschi fino al 1815 (superamento del dualismo fra archivio di spedizione ed archivio di ricezione; nascita di una organizzazione archivistica specializzata e di un nuovo dualismo fra archivio annesso ad un ufficio ed archivio principale). 1. Nascita della moderna organizzazione degli atti e della registratura ordinata per materia; 2. Brandenburgo-Prussia; 3. Baviera; 4. Austria; 5. Württemberg; 6. Sassonia; 7. Riepilogo.

CAPITOLO IX: Gli archivi moderni dalla la Rivoluzione Francese (superamento degli archivi specializzati mediante il moderno archivio di concentramento. Costituzione delle moderne amministrazioni archivistiche e istituzione degli Archivi provinciali).1. Francia; 2. Belgio; 3. Italia; 4. Spagna; 5. Portogallo; 6. America Latina; 7. Svizzera; 8. Paesi Bassi; 9. Inghilterra, Scozia, Irlanda;10. Stati Uniti d'America;11. Danimarca;12. Norvegia;13. Svezia;14. Russia; 15. Le ex provincie russe del mar Baltico: Estonia, Livonia e Curlandia. La Finlandia; 16. Polonia e Lituania; 17. Le regioni della duplice Monarchia austro-ungarica; 18. 18. Gli Archivi dello Stato Nazionale tedesco (18711945) e dei suoi Stati regionali (Cit. por la trad. Italiana de Renato Perrella, Milán, 1968.

Al estudio de estas dos obras, en lo concerniente a su relación con la historia de la archivística, nos dedicaremos en otra ocasión.

${ }^{16}$ Vid. fundamentalmente "La phase cruciale de l'histoire des archives: la constitution des dépôts d'archives et la naisance de l'archivistique (XVIème-XIXème siècle). Op. Cit 
En definitiva, el poder político y las transformaciones sociales como elementos definitorios de la evolución archivística.

Por su parte, la segmentación que establece Sandri y Lodolini ${ }^{17}$ distingue tres grandes períodos en el desarrollo de la Archivística, tres grandes épocas que determinan a su vez tres importantes y diferenciados conceptos de archivo, que se van superponiendo en los aconteceres. El primero abarcaría desde la antigüedad a principios del s. XVIII, caracterizado por un predominio del concepto patrimonialadministrativo del archivo y por la importancia del valor jurídico de los documentos. El segundo periodo ocuparía el s. XVIII y la primera mitad del s. XIX, prevaleciendo, en esta ocasión, un concepto historicista del archivo y un marcado predominio del valor histórico de los documentos. Y, por último, el tercer periodo, que englobaría los años finales del s. XIX y buena parte del s. XX, donde el crecimiento de competencias por parte de la administración y el consecuente aumento del volumen documental, propicia un concepto integrador de las dos concepciones anteriores: administrativo e histórico. En definitiva, frente a Bautier, estos autores se fijan más en el orden interno y conceptual de la archivística que en el orden externo contextual e histórico. Por ello, consideramos que ambas periodizaciones no se contraponen, sino que más bien pueden superponerse en el análisis, dado que reflejan diferentes percepciones de la evolución archivística.

En lo que respecta a autores españoles, Mendo Carmona, Cruz Mundet y Romero Tallafigo, son algunos de los que han resuelto el problema mediante sendas periodizaciones. Concepción Mendo habla de cuatro fases: archivística empírica, archivística como doctrina jurídica, archivística como disciplina historiográfica y archivística actual. Por su parte, Cruz Mundet, en un artículo anterior habla de dos períodos: el pre-archivístico, "durante el cual el tratamiento de los fondos se ha caracterizado por la indefinición de sus presupuestos e incluso por la sumisión a los principios de otras disciplinas" y el periodo de desarrollo archivístico "durante el cual tanto en la teoría como en el tratamiento de los fondos documentales se ha logrado unos niveles suficientes de autonomía como para poder hablar propiamente de archivística". Por último, Romero Tallafigo, segmenta la historia de los archivos en dos grandes períodos según las categorías del Antiguo Régimen y el del Nuevo Régimen, que se implanta paulatinamente tras la Revolución francesa. ${ }^{18}$

A modo de conclusión, expuestas las distintas periodizaciones parecen claros, al menos tres elementos: en primer lugar,

\footnotetext{
${ }^{17}$ SANDRI, L. "La storia degli archivi" Op. Cit; LODOLINI, E. Lineamenti di storia dell'archivística italiana. Dalle origini alla metà del secolo XX. Op. Cit.
}

que el s. XIX supuso una fase crucial en el desarrollo archivístico, dado que es en este momento cuando se establecen las bases teóricas y principios fundamentales de la Archivística; en segundo lugar, que el objeto archivístico circula entre una concepción empírica, funcional y jurídico administrativa, y una concepción deductiva e historicista; y por último, que los grandes cambios históricos socioculturales y administrativos influyen de forma decidida en el desarrollo de los archivos.

\section{PERÍODOS PARA UNA HISTORIA DE LA ARCHIVÍSTICA. CARACTERÍSTICAS GENERALES}

Nos proponemos ahora establecer una periodización para la historia de la archivística que atendiendo de forma sustancial al concepto mismo de archivo, no ignore el contexto social, económico, político y cultural que caracteriza las épocas de la Historia en su generalidad.

De manera que, guiados en gran medida por la excepcional contribución de Mendo Carmona, aunque con algunas pequeñas variaciones, hemos establecido cuatro grandes etapas, que deben ser manejadas con la cautela de lo que pretende ser una categorización historiográfica de los diferentes 'espacios de inteligibilidad archivística", si por ello ignorar las posibles contradicciones internas, los lapsos de inercias y las lentas formalizaciones y desintegraciones conceptuales:

1‥ La Archivística como instrumento inductivo y funcional, que se dilataría desde las primeras formalizaciones de archivos hasta la época de los Trastámaras en la Edad Media.

2ª La Archivística como doctrina patrimonial y jurídicoadministrativa, que abarcaría desde la Baja Edad Media hasta la segunda mitad del s. XVIII.

3‥ La Archivística como desarrollo historiográfico y teoría especulativa, que llegaría desde la segunda mitad del siglo XVIII, hasta la primera mitad del s. XX.

4⿳亠口.. Y, por último, la Archivística integral en la sociedad del conocimiento que se aplicaría a la archivística actual.

Veamos brevemente, de forma casi esquemática, lo que podrían ser las características elementales de cada uno de

\footnotetext{
${ }^{18}$ Respectivamente: MENDO CARMONA, C. "El largo camino de la archivística: de práctica a ciencia" Op. Cit.; ídem "Los Archivos y la Archivística: evolución histórica y actualidad”. En RUIZ RODRÍGUEZ, A.A. (Ed.) Manual de Archivística Op. Cit., pp. 19-38;CRUZ MUNDET, J.R. "Evolución histórica de la Archivística". Bilduma. 1993, 7, pp. 104-105; y ROMERO TALLAFIGO, M. "La historia de los Archivos ". En Archivística y Archivos: soportes, edificio y organización. Op. Cit., pp. 35-71.
} 
estos períodos. Reiteramos que no pretendemos analizar ni siquiera brevemente cada uno de estos rasgos identificativos, sino simplemente categorizarlos históricamente.

\section{LA ARCHIVÍSTICA COMO INSTRUMENTO INDUCTIVO Y FUNCIONAL}

El período que así hemos denominado se caracteriza por la ausencia de un corpus teórico archivístico, reconocido como tal. El resultado, por tanto, es el de una simple práctica inductiva, funcional y empírica educada por la utilidad y el ajuste racional.

Es por todos sabido cómo los archivos tienen una remota existencia, justamente aquella en la que surgen las primeras organizaciones sociales, constatándose una estrecha vinculación entre los primeros archivos y los orígenes de la escritura.

De manera que, como ya hemos comentado, este período abarcaría desde la antigüedad hasta la Baja Edad Media. Lo situamos hasta aquí, dado que es intelectualmente aceptado cómo muchas de las novedades que encontramos en los siglos XVI y XVII tienen unos antecedentes bajomedievales directos, localizados entre la creación de la Audiencia Real por Enrique II y la del Consejo Real por Juan II. A partir de entonces la administración castellana dispone de instituciones perdurables, burocratizadas y regularizadas normativamente, guiadas por funcionarios profesionalizados con obligaciones gubernativas y judiciales que comenzaban a emerger de las grandes universidades castellanas; esto es, cuando se originan de manera ajustada y reglamentada protocolos de correspondencia administrativa de los diferentes organismos entre sí y con el monarca, dando lugar a originales procedimientos administrativos, tomando el documento toma un valor patrimonial y jurídico-administrativo. ${ }^{19}$

Durante esta etapa el significado del término Archivo es el lugar donde se conservan los documentos ${ }^{20}$. En este sentido, si durante la Época Antigua parece ser que fueron los Palacios y los Templos los principales ámbitos donde se custodiaban los conjuntos documentales heterogéneos, en la Alta Edad Media serán las catedrales y los monasterios los lugares que centralizarán los documentos.

Veamos resumidamente las características más notorias para este período:

\footnotetext{
${ }^{19}$ Vid. LORENZO CADARSO, P.L. La documentación real... Op. Cit., pp. $16-17$ y ss.

20 SANDRI, L. "La storia degli archivi. Op. Cit. p. 107; LODOLINI, E. Archivistica, principi e problemi. Op. Cit. p. 50. (Cit. MENDO CARMONA, C. “Los archivos...” Op. Cit., p. 20).
}

1‥ La Archivística como procedimiento empírico. En estos momentos no existe teoría archivística específica, sino que los métodos de clasificación y ordenación de documentos son el resultado de una elemental práctica funcional. En este orden de cosas, los hábitos y conductas obedecen exclusivamente al establecimiento de los documentos como base de la práctica administrativa, no detectándose apenas interés histórico alguno. En definitiva, la doctrina se traduce en empirismo, la metodología en costumbre, los procedimientos operativos en tradición, y la finalidad en utilidad organizativa para la administración.

2ªnsideración del archivo como sujeto individual. El archivo acaece como una entidad de naturaleza original (claros ejemplos son el archeion griego y el tabularium romano), con rigurosas regulaciones jurídicas y con presencia de personal institucionalizado (encargados de la custodia con particular juramento como el areópago o el epistate, u otros asistentes especiales, como los censores y prefectos). ${ }^{21}$ En consecuencia, se alcanza paulatinamente una inserción del archivo en el contexto social y representativo, suscitándose expectativas de

${ }^{21}$ Sobre el archivo en época romana, acaba de aparecer un sugerente artículo donde se concluye que "el tabularivm es la prueba más tangible de la vitalidad del régimen municipal y de la racionalidad de su gestión administrativa". (Vid. FERNÁNDEZ ROMERO, I. "Tabvlarivm: el archivo en ápoca romana" en Anales de Documentación, 2003, 6, pp. 59-70).

${ }^{22}$ Vid. CRUZ MUNDET, J.R. “Historia ...”. En: Manual... Op. Cit., pp. 28-29.

${ }^{23}$ En realidad, en Roma, la función notarial no estuvo atribuida a una única persona, sino que se mantuvo durante largo tiempo dispersa a multitud de oficiales públicos y privados. Se conocen, al menos, tres personas que ejercían dichas funciones: el escriba, el notarii y el tabellio. Los escribas escoltaban a los pretores romanos que enviaban a provincia y su función consistía en extender las actas, escribir los decretos y custodiar en los archivos las cuentas del Estado. En este sentido, desempeñaban el oficio de escribanos al lado de las autoridades constituidas y daban fe de los actos de éstos. El notarii fue un técnico en la captación de la exposición oral de un tercero para pasarla por escrito con celeridad valiéndose de signos, abreviaturas, cifras, etc. Sin embargo, son los tabullarius y el tabellio los considerados como los principales antecedentes romanos del notariado. El tabullarius es una especie de archivero de documentos privados, además de desempeñar las funciones oficiales del censo. Aparecen en el período post-clásico, que termina con la codificación justinianea, y formalizaban documentos contractuales, redactaban escritos judiciales, extendían declaraciones testificales y formulaban, extendían y suscribían testamentos En consecuencia, era el encargado de custodiar testamentos, contratos y documentos con objeto de salvaguarda jurídica y de derechos. Su carácter jurídico se expresa detenidamente en la Novela 44 de Justiniano según la cual deben conocer el contenido y los efectos de la ley. Se atribuyó completa credibilidad al documento emanado del tabellio, siendo, en determinadas ocasiones, su testimonio dirimente, como en los casos de impugnación del instrumento. El carácter autentificador se fundamentaba no tanto en el contenido de los documentos privados cuanto en su entrega y custodia. En definitiva, se trata de claros antecedentes notariales, si bien falta aún la función legal de dar forma solemne a los actos formalistas. (Vid. entre otros BONO, José. Historia del Derecho Notarial Español. Junta de Decanos de los Colegios Notariales de España. Madrid, España. 1979; GIMÉNEZ ARNAU, Enrique. Derecho Notarial. Ediciones Universidad de Navarra, S. A. Pamplona: 1976; o la síntesis de V. París Hernández Bieletto El derecho notarial y sus perspectivas para el s. XXI...Op. Cit.). 
El tiempo de la archivística - un estudio de sus espacios de racionalidad histórica

evidencia documental y vigencia jurídica. ${ }^{22}$ En definitiva, el archivo irá quedando convertido en el lugar donde se conservan los monumentos escritos, con existencia propia e independiente, y con el objeto de testimoniar los negocios administrativos y jurídicos.

3‥ El Archivo como agente de la función administrativa. Se es consciente que los documentos son creados y conservados por necesidades de gobierno y administración, con un interés notable: la garantía jurídica. El derecho romano avalará los principios del archivo de instrumento jurídico, valor probatorio y salvaguarda de derechos. Pensemos, por ejemplo, en los tabellio romanos que ejercían la función notarial, y que se denomina "fe pública", mediante la cual, se daba reconocimiento del pleno valor probatorio de los documentos emitidos por estas personas. ${ }^{23}$

4⿳亠口冋. Aparición del concepto de Archivo Público, no sólo en cuanto a su propietario sino también en cuanto a la noción de conferir fe pública a los documentos. El archivo, en consecuencia, como testimonio de la gestión y como soberanía de las atribuciones. ${ }^{24}$

5‥ Avances en el "tratamiento archivístico". Es evidente que el desarrollo de las oficinas y archivos en época romana influye decididamente en el despliegue archivístico. Así, al decir de los diferentes autores - Cencetti, Posner, A. D'ors, Mendo Carmona, Rodríguez Neila, Muñiz Coello, etc. - encontramos en la organización documental avances relevantes, que si bien no obedecen a principios teóricos aceptados globalmente, sí que prácticamente supusieron mejoras para la resuelta actividad y funcionalidad administrativa romana. ${ }^{25}$

Más tarde, la caída del Imperio Romano supuso un grave retroceso en el devenir archivístico, motivado en gran

\footnotetext{
${ }^{24}$ Un buen ejemplo, de todo esto son los documentos que se incluyen en el tabvlarivm romano como reflejo de las instituciones municipales: commentarium, actas, decreta decurionum, documentos del erario municipal, propiedades públicas municipales, catastro, etc. (Vid. para todo ello: FERNÁNDEZ ROMERO, I. "Tabvlarivm: el archivo en ápoca romana" Op. Cit., pp. 64-67).

${ }^{25}$ Vid. CENCETTI, G. "Gli archivi dell'antica Roma nell'età repubblicana" en Archivi, 1949, II, pp. 7-49; ídem."Tabularium principis" en Scritti archivistici, Roma, 197o, pp. 221-259;POSNER, E. Archives in the ancient world, Cambridge, 1972; RODRÍGUEZ NEILA, J.F. "Archivos municipales en las provincias municipales del Imperio Romano" en Veleia,1991-92, no 8-9, pp. 145-174; MUÑIZ COELLO, J. "Elaboración, conservación y custodia de las fuentes documentales escritas en la antigua Roma. Los Archivos (II)" en Hispania Antiqua, 1998, 22, pp. 371-400, o MENDO CARMONA, C. "Los archivos y la archivística: evolución histórica..." Op. Cit. Para esta autora los "documentos procedentes de una misma función administrativa se ordenaban siguiendo un orden cronológico”, esto es, practicando empíricamente el conocido principio de procedencia, sin que esto signifique que hubiese alguna formulación teórica al respecto. De este modo, cada oficina guarda la documentación generada naturalmente para la realización de sus actividades y funciones de forma cronológica en diferentes galerías del Tabularium (pp. 29).
}

medida por el detrimento creciente del documento escrito y la sustitución del carácter probatorio de éste por la palabra y la demostración testifical. Al mismo tiempo, se produjo un retroceso de la organización administrativa, mayores ámbitos de ruralización, una disminución del uso de la escritura, casi la completa desaparición de la complejidad administrativa que se había desarrollado en Roma, un paulatino desmantelamiento de la red de archivos del Imperio ${ }^{26}$, y un desmoronamiento de la idea de archivo público, dado que del Estado como res pública se pasó a la consideración del Estado como propiedad personal de quien ejercía el gobierno.

\section{LA ARCHIVÍSTICA COMO DOCTRINA PATRIMONIAL Y JURÍDICO-ADMINISTRATIVA}

Durante este período la archivística se desarrolla como una doctrina patrimonial y jurídica al servicio de la administración. Es el momento en que comienza su sistematización como disciplina aunque sin sentar aún unos principios teóricos universales. El archivo se convirtió en un elemento fundamental de la maquinaria administrativa y, por tanto, adquirió una función predominantemente jurídico-política, al ofrecer a los soberanos una documentación útil para la afirmación de los derechos de la Corona y del Estado, y para el ejercicio del poder en sus territorios. Es éste un proceso lento, que tiene su inicio en la Baja Edad Media, que quedará consolidado con un nuevo sistema administrativo, el Estado moderno, y que más tarde desaparecerá con las revoluciones burguesas del s. XVIII.

Veamos brevemente las características de este período:

1‥ La Archivística como doctrina jurídica al servicio de la administración, esto es, y para no reiterarlo m's, como instrumento social y administrativo. Asimismo, y en consecuencia, tal y como todos los teóricos indican, hay una mejora de las técnicas de tratamiento archivístico.

2ª . Desarrollo de la organización administrativa y complejidad de la práctica documental. La recuperación económica, una mayor complejidad institucional y administrativa, la recuperación del derecho Romano y del procedimiento administrativo que le sostenía, y la conformación del Estado Absoluto, hicieron factible la recuperación del documento como fundamento de la organización

\footnotetext{
${ }^{26} \mathrm{La}$ legislación de Justiniano sobre el tema, tratando de responder a los abusos que se venían produciendo, restringió la facultad para crear archivos a las autoridades con capacidad para legislar (emperadores, soberanos, pontífices) y estableció limitaciones a la capacidad del archivo para dar fe de autenticidad a los documentos en él depositados, obligando a que fuesen escriturados con determinadas formalidades (Cfr. DORS, A. Documentos y notarios en el derecho romano post-clásico. Madrid, 1964).
} 
jurídico-política. Como consecuencia de todo ello, el Archivo queda transformado en instrumento base de la organización administrativa del Estado. La creciente complejidad de ésta y su burocratización progresiva se traducía en una práctica documental cada vez más embarazosa. El resultado de todo ello para la Europa Occidental fueron los Archivos de Estado. En ellos se concentró toda la documentación generada por las coronas, que se había mantenido dispersa hasta entonces. En palabras de Rodríguez de Diego, "la trascendencia de la sedentarización de los archivos administrativos es pareja a la trascendencia de la sedentarización de los órganos de que dimanan". ${ }^{27}$

3‥ Archivos del poder. Tal y como hemos dicho, el archivo es uno más de los mecanismos de poder de las monarquías absolutas, esto es, uno de los procedimientos de dominio y control. Es lo que se viene denominando como "la función coercitiva del archivo". ¿Y en qué se basa dicha función? En tres aspectos: primero, el carácter de patrimonialidad del archivo, es decir, la atribución del archivo como atributo del rey; segundo, el secretismo, esto es, el temperamento inescrutable y sacro del archivo; y tercero y fundamental, la inaccesibilidad del archivo. ${ }^{28}$ En definitiva, la concepción del archivo como poder radica precisamente en "que la garantía del derecho del súbdito dependía de la voluntad del monarca a través de un despacho expedido por el órgano institucional, cuya función era exactamente la concesión de la gracia y, por ello, la actividad más representativa de su carácter absolutista"29.

4… Desarrollo de la literatura archivística. Desde finales del s. XVI y a lo largo de los siglos XVII y XVIII surgen una serie de tratadistas que desarrollan la literatura archivística con contribuciones nada desdeñables tanto en sus planteamientos especulativos como en sus empeños experimentados y técnicos. ${ }^{30}$. Por su parte, en el propio territorio de la Monarquía Hispánica se

\footnotetext{
${ }^{27}$ Cfr. RODRÍGUEZ DE DIEGO, J.L. "Archivos de poder, Archivos de la Administración, Archivos de Historia (siglos XVI-XVII)" Op. Cit., p. 37.

28 Son fundamentales los trabajos de RODRÍGUEZ DE DIEGO, J.L. "Archivos de poder, Archivos de la Administración, Archivos de Historia (siglos XVI-XVII)" Op. Cit. p. 31 y ss.; y "La formación del Archivo de Simancas en el s. XVI. Función y orden interno". En LÓPEZ VIDRIERO, Mํㅡ. L. y CÁTEDRA, P. El libro Antiguo Español IV. Coleccionismo y biblioteca. Siglos XV-XVIII. Salamanca: Universidad de Salamanca. Patrimonio Nacional. Sociedad Española de Historia del Libro, 1998, pp. 519-557.

${ }^{29}$ Cfr. RODRÍGUEZ DE DIEGO, J.L. "Archivos de poder, Archivos de la Administración, Archivos de Historia (siglos XVI-XVII)" Op. Cit., p. 33. (Véase al respecto la explicación que da este autor sobre el procedimiento empleado para solicitar y obtener copias de escrituras. Ibídem, pp. 3134). Al respecto, también DE DIOS, S. Gracia, merced y patronazgo real. La Cámara de Castilla entre 1474 y 1530. Madrid, 1993, incluyéndose la tramitación de las solicitudes a través del Consejo de la Cámara como una gracia o merced real).
}

realizaron abundantes títulos - informes e instrucciones por lo general - acerca de la práctica documental y sus proyecciones. ${ }^{31}$ Pues bien, todo ello tuvo un efecto enormemente positivo en la creación paulatina de un cuerpo doctrinal archivístico, a pesar de que los aspectos más perseverantes y sólidos seguían viniendo del campo de la praxis archivística. Por primera vez se buscan respuestas concretas a problemas reales, suscitándose hipótesis que deberán ya ser tenidas en cuenta en el futuro a efectos de clasificar, ordenar y describir documentos y que tanto incidirán en la doctrina jurídica de la archivística.

5‥ Archivos para la eficacia administrativa. La relación entre archivos y administración es bilateral; si por un lado las reformas administrativas condicionan la evolución cuantitativa y cualitativa de los archivos, por otro, éstos inciden en el desarrollo de aquéllas y en su mayor funcionalidad pragmática. Reformas administrativas y despliegue archivístico, en consecuencia, como factores que se retroalimentan. En este orden de cosas, el archivo es considerado como entidad necesaria para el funcionamiento administrativo (piénsese en la exigencia de pruebas en los numerosos procesos, los copiosos documentos de juicio de

${ }^{30}$ De finales del s. XVI destaca Jacob von Rammingen (Von der Registratur und jren Gebäwen und Regimenten. Heidelberg, 1571 y Summarisches Bericht was es mit einer Künstlichen und volkommenen Registratur fur eine Gestalt. Heidelberg, 1571). Del s. XVII, Baldassarre Bonifacio (De archivis liber singularis. Venecia, 1632), Nicoló Giussàni (Methodus archiviorum, seu modus eadem texendi ac disponendi. Milán, 1684), Albertino Barisone (Commentarius de archivis antiquorum. s.l., s.a. (entre 1619 y 1636), y Ahasver Fritsch (Tractatus de jure archivi et cancellariae, Jena, 1664). Del s. XVIII, Pierre Camille Lemoine (Diplomátique pratique, ou traité de l'arrangement des archives et trésor de chartes. Metz, 1765), B. de Bonvoulou (L'archiviste françois ou méthode sûre pour apprende à arranger les archives et déchiffrer les anciennes écritures. París, 1775), J.G. Chevrières (Le nouvel archiviste, contenant une nouvelle méthode de ranger un chartier dont l'ordre chronologique est le base. París, 1778), Johann Stephan Pütter (Auleitung zur juristichen praxis. Gotinga, 1777) y Georg August Brachmann (Über Archive, deren Natur und Eigenschaften, Einrichtung uns Benutzung nebst praktischer Anleitung für angehende Archivbeante in archivalischen Bescchäftigungen. Amberg-Sulzbach, 1801). (Son útiles las referencias que se hacen a estos autores en las obras de E. Casanova ya citada).

${ }^{31}$ Destacan: AGUSTÍN Y RIOL, S. Informe que hizo a Su Majestad, en 16 de junio de 1726 [...] sobre la creación, erección e institución de los Consejos y Tribunales [...]. Fue publicado en el Seminario Erudito de Valladares Sotomayor, 1787, III, pp. 74-236; MELCHOR DE JOVELLANOS, G. Instrucción formada por el Sr. D. Gaspar Melchor de Jovellanos, del Consejo de S.M. en Real de las Órdenes, para el arreglo del Archivo del Monasterio de S. Spiritus de Salamanca, en virtud de comisión de dicho Real Consejo. Salamanca, 1790; ́dem. Noticia del principio, progresos y último estado del Archivo General de la Orden de Santiago en el Real Convento de Uclés, mandado publicar por el Real Consejo de las Órdenes. Madrid, 1791. Al margen, hemos de apreciar la manifestación de tratados de paleografía. Estos, en gran medida, motivan la aparición de nuevas suposiciones conceptuales que serán de enorme trascendencia en el futuro inmediato de nuestra disciplina, con acciones que iban desde la oerganización documental hasta su descripción. En este sentido, son importantes los tratados de Paleografía de C. Rodríguez (Bibliotheca universal de la Polygrafia española. Madrid, 1738) o los de E. de Terreros y Pando, A. Merino de Jesuchristo, etc. 
imprescindible formalidad para cuantiosas cuestiones), y, por tanto, de eficacia relevante tanto para la administración como para los administrados.

6‥ Elemental y embrionaria red de archivos. La cada vez mayor organización territorial de la administración, la paulatina jerarquización de organismos, la progresiva interdependencia entre ellos, y la concreción de sus funciones y actividades en unos determinados marcos geográficos, son factores influyentes en la pausada confección de una red de archivos en las Monarquías Absolutas. Contamos con archivos de Estado, con archivos locales, con archivos de organismos intermedios - como son los Adelantamientos - con archivos de Cortes, con archivos foráneos y con abundantes archivos de otros entidades que se escapan al tronco de la administración. Se cuenta, por tanto, con un importante boceto de red de archivos basado en el organigrama institucional cada vez más burocratizado, aunque todavía con ausencias de articulación entre sus órganos, como corresponde a un estado monárquico y señorial. ${ }^{32}$

\section{LA ARCHIVÍSTICA COMO DISCIPLINA HISTORIOGRÁFICA Y TEORÍA ESPECULATIVA}

Nos adentramos a continuación en una etapa especialmente relevante para la historia de la Archivística y su desarrollo como disciplina independiente. Será en este momento cuando se establezcan determinados enunciados teóricos o principios generales sobre los que se desarrollará posteriormente el complejo entramado conceptual, y que dan a la Archivística el rango de saber científico en consolidación. Nos referimos fundamentalmente al Principio de Procedencia o Principio del Respeto de los Fondos.

El desmantelamiento del Antiguo Régimen, los nacionalismos germinados venidos de la mano del romanticismo ideológico o la historiografía positivista prestarán singulares sustratos metodológicos a la archivística, empleándola como instrumento al servicio de la Historia científica. Aproximadamente, los límites cronológicos pueden quedar situados hacia el segundo tercio del s. XX, momento en que la Archivística se enfrenta a nuevas funciones y retos, causados esencialmente por la extensión de su campo de actuación a los niveles administrativos, el desarrollo tecnológico o las nuevas necesidades informativas.

Veamos escuetamente, pues, las características de la etapa que ahora nos ocupa:

${ }^{32}$ RODRÍGUEZ DE DIEGO, J.L. Instrucción para el gobierno del Archivo de Simancas. Op. Cit., pp. 43-53.
1‥ La Archivística como disciplina historiográfica. Con la demolición del Antiguo Régimen un número ingente de documentos cesaron de súbito en su función primaria de garantes de prueba, materialización de privilegios, protección de jurisdicciones y aval de actuaciones, lo cual había justificado el esfuerzo de numerosas instituciones para mantener los documentos y archivos reservados y conservados. Al mismo tiempo, y complementariamente, durante el s. XIX aparece en Europa una fuerte impronta nacionalista, necesitada de fuentes para encontrar las raíces comunes y las identidades colectivas. En consecuencia, los documentos archivísticos representan la prueba legendaria, los elementos imprescindible sobre los que basar la distinción histórica que se exige ineludiblemente para la construcción de los movimientos identitarios. ${ }^{33}$ Como consecuencia de ambos agentes, fue necesario centralizar la documentación en depósitos trazados para el análisis histórico. Son los Archivos Históricos y Archivos Nacionales ${ }^{34}$

En definitiva, el concepto de archivo adquiere una nueva dimensión, al definirse no sólo por su carácter patrimonial o administrativo, sino sustancialmente por su finalidad histórica. En palabras de R. H. Bautier, los archivos resultan ser "laboratorios de la historia". 35 Prueba de ello es que la archivística es una más de las ciencias auxiliares de la Historia - como lo son la Diplomática o la Paleografía -, el que los responsables al frente de los archivos no fueran funcionarios con formación administrativa y jurídica sino investigadores amantes de la historia, o el que el objeto fundamental de estudio de la archivística fuera el documento aislado e individualizado, con influencia clara de las técnicas diplomáticas, frente al estudio del archivo en sí como conjunto orgánico de documentos. Así pues, el archivo queda convertido, de nuevo, en pieza clave del nuevo régimen, en esta ocasión para la realización de la Historia.

2-. Formalización de la Teoría Archivística: el Principio de Procedencia. Si hay algo que hace concebir a la Archivística como disciplina científica es el desarrollo teórico de que gozó durante esta etapa. Y al decir de todos los todos los teóricos el fundamento y sostén de dicho desarrollo lo conforma el Principio de Procedencia. Éste se configura

33Vid. d'ADDARIO, A."Lineamenti di storia dell'archivistica (sec. XVIXIX)". Op. Cit., p. 23.

${ }^{34}$ Son los denominados por Brenneke, "archivos de concentración". (BRENNEKE, A. Archivkunde: ein Beitrag zur Theorie und Geschichte des europäichen Archivwesens. Leipzig, 1953. Hay trad. italiana: Archivistica: contributo alla teoria ed alla storia archivistica europea. Milano: Giufré, 1968, p. 17 y ss.).

35 Vid. "La phase cruciale..." Op. Cit., p. 149. 
como centro neurálgico de la teoría archivística, sobre el cual se va acumulando todo el entramaje especulativo que la praxis archivística debe siempre respetar. De forma simplista, pero con consecuencias formidables, dicho principio afirma, por un lado, que los documentos provenientes de una procedencia deben estar reunidos y sin mezclarse con los de otra procedencia, y por otro, que dichos documentos deben mantenerse ordenados naturalmente, esto es, respetando la funcionalidad y organización institucional ${ }^{36}$.

Dicho Principio no es resultado de un único momento ni sucede en un único lugar a pesar de la pugna por adjudicarse la paternidad del mismo ${ }^{37}$. Son características las aplicaciones puntuales en el tiempo, el largo proceso de teorización y sistematización, la conciencia creciente de su necesidad, su pausada expansión geográfica y las evoluciones muy particulares para cada país ${ }^{38}$. Sin embargo, lo que debe quedar claro, es que mediante su formulación, debate, aplicación práctica y universalización quedaron cimentadas las bases para el desarrollo de la teoría archivística moderna.

\section{3‥ Desarrollo de la descripción en Archivística y de la} elaboración de instrumentos heurísticos. La disposición de la Archivística como disciplina dependiente de la investigación histórica tiene como consecuencia directa el despliegue de la descripción documental a través de las diversas herramientas heurísticas. El objetivo es que el historiador tenga cuantas más facilidades mejor para su investigación científica, esto es, que encuentre el dato ansiado, el documento necesitado. Es, pues, el momento de los catálogos sistemáticos, de los índices y guías, de las recopilaciones documentales, de las colecciones diplomáticas. ${ }^{39}$

4⿳亠口冋. Despliegue de la formación profesional específica, creación de grandes centros de enseñanza archivística y

\footnotetext{
${ }^{36} \mathrm{Su}$ desarrollo teórico e s base de cualquier manual al uso. A ellos nos referimos para repetir lo ya conocido.

${ }^{37}$ Para España son fundamentales dos obras: la de Froilán Troche y Zúñiga (El Archivo cronológico-topográfico. Arte de archiveros. Método fácil, sencillo y poco costoso para el arreglo de los Archivos particulares, útil a los Hacendados y poseedores de bienes que tienen documentos para conservar sus intereses, arreglo interior y económico de las casas, dirección y manejo de los intereses de ellas. Coruña: Imprenta de Iguereta, 1835 (2 ${ }^{\underline{a}}$ ed. cor.)), y la de Facundo de Porras Huidobro (Disertación sobre archivos y reglas de su coordinación, útil para todos los que los tienen o manejan. Madrid: Imprenta de D. León Amarita, 1830). (Vid. el excepcional artículo del profesor FUSTER RUIZ, F. "Los inicios de la Archivística española y europea". Revista General de Información y Documentación.1996, Vol. 6, no 1, pp. 43-77).

${ }^{38}$ Por ejemplo, para el caso de Italia Vid. LODOLINI, E. Lineamenti di storia dell'archivística italiana. Dalle origini alla metà del secolo XX. Op. Cit.; para el caso de Alemania, Vid. POSSNER, E. "Max Lehmann y el origen del principio de procedencia”. En MUNDEN, K. (Ed.) Archives and the Public Interest. Selected Essays by Ernst-Posner. Washington, 1967, pp. 36-44.
}

desarrollo legislativo archivístico. Desde finales del s. XVIII surgen en toda Europa Escuelas específicas de formación profesional archivística. ${ }^{40}$ De esta manera, en 1856, se instituye en Madrid la Escuela Superior de Diplomática, factor relevante para la evolución de la lenta formación profesional de la disciplina, que, aunque con no pocos altibajos, pasó de ser autodidacta y en el propio archivo a enseñanza oficial en universidades. Como consecuencia, durante el s. XIX se produce una auténtica revolución legislativa en lo que a materia archivística corresponde. ${ }^{41}$

Por consiguiente, se observa cómo en la historia de nuestra disciplina, y de forma clara en esta época, se produce un paralelismo cardinal con la acción política. Dicho de otra forma, la Archivística a partir de este momento posee un mayor grado de oficialidad, motivado sustancialmente por las sistemáticas reformas administrativas que se suceden, y que ocasionan que los gobiernos de turno sintieran la obligación de

${ }^{39}$ Ya lo dice C. Mendo en su excepcional síntesis. (Vid. "Los Archivos y la Archivística..." Op. Cit., p. 30). Por otro lado, al decir de d'Addario se distinguen dos escuelas o maneras de proceder en la descripción: una, de características analíticas, basada en el análisis de los documentos de forma pormenorizada, con influencias positivistas y con dependencia de la paleografía y la diplomática; y otra, de cualidades más sintéticas, fundamentada en el análisis del mayor número de documentos posibles, con objeto de hacer grandes visiones de conjunto al historiador y ofrecerle noticia de amplios volúmenes documentales. (Vid. D'ADDARIO, A. A."Lineamenti di storia dell'archivistica (sec. XVI-XIX)". Op. Cit., pp. 28-29. Cit. CRUZ MUNDET, J.R. Manual... p. 47).

${ }^{40}$ Así, en Italia había estudios específicos en las universidades de Bolonia (1765), Milán (1770) y Nápoles (1777), y más tarde en los archivos y a partir de 1857 en la Scuola de Paleografia e Diplomatica de Florencia; en Portugal, en la Universidad de Coimbra se creó en 1796 el Aula Diplomática; en Francia, en 1821 lo hace en París la famosa École des Chartres; en Austria se crea en 1854 el Institut für Oesterreichische Geschichtsfurung.

${ }^{41}$ Primeros intentos de establecer Cátedras de Historia Literaria y Bibliografía y Numismática; títulos de Revisor de Letras Antiguas y de Revisores y lectores de letras antiguas y Revisores de firmas y papeles sospechosos; creación de la Cátedra de Paleografía en 1838; Real Decreto de Noviembre de 1847 que crea una Junta Superior Directiva, más tarde una Dirección General de los Archivos de España y Ultramar; Real Decreto de octubre de 1856, mediante el cual se creaba la Escuela Superior de Diplomática; Ley de Instrucción Pública, o Ley Moyano, de septiembre de 1857 , que puso las bases para la organización de los archivos que quedaron vinculados al Ministerio de Instrucción Pública, creó la Junta Superior Directiva como órgano consultivo y técnico, e instituyó el Cuerpo Facultativo de Archiveros, Bibliotecarios y Arqueólogos; reglamentos para el servicio de de los principales archivos (1887-1901); Supresión por Real Decreto de julio de 1900 de la Escuela Superior de Diplomática, refundiéndose sus estudios en la Facultad de Filosofía y Letras de la Universidad Central; Real Decreto de mayo de 1932 por el que se acomete la reorganización del Cuerpo Facultativo, etc. (Para todo ello son interesantes algunas contribuciones de L.M. de la Cruz Herranz "Panorama de los archivos españoles durante el s. XIX y primer tercio del s. XX" en Historia de los Archivos y de la Archivística en España... Op. Cit., pp. 119-160); Agustín Torreblanca López "La Escuela Superior de Diplomática y la política archivística del s. XIX" en ibídem, pp. 71-118, etc.- vid nota siguiente). 
la regulación documental a través de una política archivística. $^{42}$

5*. Conquistas de la literatura teórica y asentamiento paulatino de la Archivística moderna. Otra de las características fundamentales de la etapa que analizamos es la profusión de obras de teoría archivística, propiciadas, como hemos visto, por su principal instrumento de formalización especulativa, esto es, el Principio de Procedencia. En consecuencia, contamos con una pléyade de obras que, más allá de lo que de forma estricta supone dicho Principio, teorizan sobre distintos problemas archivísticos, nos ofrecen distintas alternativas, consideran las distintas operaciones del tratamiento metodológico archivístico y nos permiten conocer la importancia y el valor de los archivos. ${ }^{43}$

\begin{tabular}{l}
\hline 42 La bibliografía es abundante. Para España, vid. ÁLVAREZ COCA, \\
Ma J. y LÓPEZ GÓMEZ, P. "Hacia un centro de formación de archiveros, \\
bibliotecarios y museólogos del País Vasco". En Actas del Décimo Congreso \\
de Estudios Vascos: Archivos, Bibliotecas y Museos. Iruñea, 21-25 de abril de \\
1987. San Sebastián, 1988, pp. 263-265; FONTANA, J. "La historiografía \\
española del s. XIX: un siglo de renovación entre dos rupturas". En \\
CASTILLO, S. (Coord.) La Historia social en España. Actualidad y \\
perspectivas. Actas del I Congreso de la Asociación de Historia Social. Op. \\
Cit.; BORDONAU MAS, M. "Formación profesional de los archiveros \\
en España". Boletín del Archivo General de la Nación. Op. Cit.; MENDO \\
CARMONA, C. y TORREBLANCA LÓPEZ, A "Los orígenes de la \\
enseñanza de la Archivística en la Universidad Central de Madrid". SIGNO. \\
Revista de Historia de la cultura escrita. Op. Cit.; PASAMAR ALZURIA, G. \\
y PEIRÓ MARTÍN, I. Historiografía y práctica social en España. Op. Cit.; \\
idem. La Escuela Superior de Diplomática. (Los Archiveros en la Historiografía \\
Española Contemporánea). Op. Cit.; RUIZ CABRIADA, A. Bio-bibliografía \\
del Cuerpo Facultativo de Archiveros, Bibliotecarios y Arqueólogos, 1858- \\
1958. Op. Cit.; TORREBLANCA LÓPEZ, A. "Erudicción institucional \\
en el siglo XIX español. La sección de Archivos del Cuerpo Facultativo \\
de Archiveros, Bibliotecarios y Arqueólogos" . En Erudicción y discurso \\
histórico: Las Instituciones europeas. Siglos XVIII-XIX. Op. Cit.; ídem. "La \\
Escuela Superior de Diplomática y la política archivística del siglo XIX". \\
En GENERELO, J.J. y MORENO LÓPEZ, Á. Historia de los Archivos y \\
de la Archivística en España. Op. Cit, pp. 71-118).
\end{tabular} ${ }^{43}$ TROCHE Y ZÚÑIGA, F. El Archivo cronológico-topográfico... Op. Cit., 1828; PORRAS HUIDOBRO, F. Disertación sobre archivos y reglas de su coordinación...Op. Cit., 1830; AA.VV. "Archivo". En Edición de la Enciclopedia Española de Derecho y Administración, ó Nuevo teatro Universal de la Legislación de España e Indias. Madrid: Imprenta de los Señores Andrés y Díaz, 1851, Vol. IV, pp. 491-554; URBINA, J. y FUENTE, V. de la. Revisión y arreglo del Archivo de la Universidad de Salamanca. Ms. 381 de B.U.S.A.; Junta Superior Directiva de Archivos. Instrucciones y Bases para el arreglo y clasificación de los Archivos. 1860. A.G.A. Educación. Caja 6.558-15; VELASCO Y SANTOS, M. "Sobre la organización de archivos". Revista de Archiveros, Bibliotecarios y Museólogos, 1875, V, pp. 141-146 y 177-185; GÚEMES y VILLAME, J. Organización del Archivo de la Corona aplicada a los archivos particulares. Madrid: Imprenta, Estereotipia y Galvanoscopia de Aribau y Cia., Impresores de Cámara de S.M., 1876. En 1875 había publicado: "Sobre la organización de los Archivo". Revista de Archivos, Bibliotecas y Museos, 1875, 13, pp. 213-218; RODRÍGUEZ MIGUEL, L. Manual del archivero ó sea teoría y práctica de arreglo y clasificación de los archivos de las diputaciones, beneficiencias y gobiernos de provincias, ayuntamientos y administraciones económicas. Toledo: Imprenta de Cea, 1877; RUBIO Y BORRÁS, M. Manual del Archivero de Hacienda. Burgos: Tipografía El Castellano, 1908. etc. (Vid. FUSTER RUIZ, F. "Los inicios de la Archivística española y europea”. Op. Cit.).
Del mismo modo, fuera de España, la literatura teórica también es copiosa durante el s. XIX y primeros años del s. XX. En este sentido, quizás convenga recordar un Manual que es considerado como uno de los primeros resultados científicos de la disciplina, dado que sistematiza de forma coherente la teoría archivística. Se trata de la obra de los archiveros holandeses Samuel Muller, J.A. Feith y Robher Fruin (1898). Más tarde vendrían los de Hilary Jenkinson, Eugenio Casanova, Adolf Brenneke o L. Cassese. ${ }^{44}$

6⿳. Incipiente desarrollo de los Archivos Administrativos. Aproximadamente en la década de los 30 se comienzan a vislumbrar algunas de las características que veremos consolidar en la segunda mitad de siglo. Hacemos referencia al despliegue de la disciplina hacia los archivos administrativos, motivado en gran medida, no sólo por el número ingente de documentos que se generan gracias a los nuevos medios, sino también al mayor desarrollo de las diferentes administraciones y el consiguiente aumento de la burocratización, la complejidad de la práctica administrativa y documental, o el incremento de los mecanismos de comunicación administrativa y sus procedimientos. En consecuencia, empiezan a ser necesarios, no ya historiadores eruditos interesados por el análisis histórico, sino técnicos capaces de organizar la numerosa documentación que se genera en las múltiples oficinas administrativas, y que son de necesaria consulta en los quehaceres diarios. Frente a la investigación, la eficacia y la rentabilidad administrativas. Así surge en Estados Unidos la doctrina del Management o gestión, y dentro de ella, la del Record Management o gestión de documentos.

\section{LA ARCHIVística INTEGRAL EN LA SOCIEDAD DE LA INFORMACIÓN}

Es el período donde la archivística cobra un especial desarrollo tanto en los principios conceptuales como en su aplicación práctica, lográndose unos niveles de autonomía desconocidos hasta el momento, lo cual permite hablar propiamente de saber consolidado. Aproximadamente, hacemos mención a la Archivística de la última mitad

\footnotetext{
${ }^{44}$ MULLER, S. , FEITH, J.A. y FRUIN, R. Handleiding voor het ordenen en beschrijven vfan archieven. Haarlem, 1898; JENKINSON, H. A manual of archive administration. $2^{2}$ ed. Londres: Percy Lund, Humphries and C. LTD, 1966; CASANOVA, E. Archivistica. Siena: Lazzeri, 1928. Archivkunde. Ein Beitrag zur Theorie und Geschichte des europäischen Archivwesens. Leipzig, 1953. Se trata de los apuntes tomados por Wolfgang Leesch de las lecciones impartidas por A. Brenneke en la Universidad; más sectorial es el de CASSESE, L. Introduzione allo studio della archivistica. Roma, 1942. Pueden ser citados también: CHAMPOLLION-FIGEAC, A. Les Archives départamentales de France. Manuel de l'archiviste des préfectures, des mairies et des hospices. Paris, 1860; DESJARDINS, G. Le service des Archives Départamentales. Paris, 1890; o TADDEL P. L’Archivista. Milán, 1906.
} 
de siglo, que recoge influencias de una doble tradición: la europea -que a través de la consolidación del estado moderno y las ideologías políticas surgidas en el s. XIX, nos vincula más al derecho y a la historia - y la norteamericana - que a través del desarrollo capitalista e industrial nos acerca más a las organizaciones privadas y la gestión administrativa.

No nos podremos extender aquí en explicitar el vertiginoso desarrollo de la disciplina en las últimas décadas. Sin embargo, considero que, aún de forma esquemática y somera, las propiedades fundamentales de la Archivística actual podrían quedar representadas en las siguientes ideas:

1‥ Ampliación del campo de actuación de la Archivística. En mi opinión con dos consecuencias de gran relieve: por un lado, una nueva concepción de la Archivística de perfil integrador, y, por otro, la inexorable parcelación del universo profesional.

Durante este período, el espacio de acción de la disciplina archivística se ha expandido a la gestión administrativa. Dicho de otra forma, las administraciones modernas de la segunda mitad del s. XX, en su propagación y extraordinario acrecentamiento, tienen recias necesidades informativas $y$, en consecuencia, exigen tratamientos adecuados y solícitos para la documentación administrativa generada. Encontramos, pues, una considerable transformación conceptual del objeto archivístico, rebasándose las inquietudes meramente históricas para llegar a una concepción global del documento. Ello queda representado mediante la acuñación del concepto "ciclo vital de los documentos" que cincela la formalización teórica de la archivística. ${ }^{45}$

De manera que el objeto de estudio comienza en la gestión documental en las oficinas correspondientes y alcanza hasta su conservación definitiva con fines históricos, incluyéndose todos los peldaños intermedios. En definitiva, el campo de acción de los profesionales de la archivística se desarrolla sobremanera, convirtiéndose, por tanto, además de en los habituales custodios de la documentación histórica, en gestores documentales administrativos. Por otro lado, el ámbito empresarial -y privado, en general- incrementa el clásico marco de las administraciones públicas, deviniendo así un incremento sustancial, a la par que unificador, del proceso documental.

\footnotetext{
${ }^{45} \mathrm{Cfr}$. PENN, I.A. "Will the real records management stand up?". ARMA. 1981, vol. 15, no 3, pp. 10-12.

46"La ampliación del dominio archivístico ha llevado, asimismo, a la partición del mundo profesional y de manera muy destacada en los países anglosajones, donde se establecen dos áreas: la del records management o gestión de documentos administrativos y la tradicional o administración de archivos" (en CRUZ MUNDET, J.R. Manual... Op. Cit., p. 52).
}

En consecuencia, y como fruto de dicha ampliación del dominio archivístico, se ha llegado a una parcelación del universo profesional, fundamentalmente en los países del área anglosajona, de matices inquietantes. ${ }^{46}$

Así pues, el saber archivístico se configura como disciplina científica que tiene por objeto de estudio todo tipo de archivos, sea cual sea la edad de los documentos que contenga. Su "ecumenismo" abarca desde que el documento nace en las oficinas - incluso antes - y se integra en un fondo de archivo, hasta que mediante métodos, normas y sistemas presta servicio a la administración, al ciudadano y al investigador. Gestión de documentos, y organización y administración de archivos como aptitudes que conforman la materia archivística.

2ª Expansión científica de la Archivística. Claramente percibido, bajo nuestro criterio, por cinco características: un progreso historiográfico de la literatura archivística, un importante desarrollo normativo, un despliegue de la política internacional de archivos, un indiscutible aumento del asociacionismo profesional y, como no, el reconocimiento oficial de la Archivística en la Universidad española.

La literatura profesional se acrecienta, yo diría, que casi de forma exponencial, evolucionando al ritmo de las nuevas necesidades. La presencia de nuevos manuales, como recopiladores y síntesis de la formalizción teórica dan buena prueba de ello. Desde los de A. Brenneke, A. Panella, T.R. Schellenberg, A. Ciceri, J. Favier, en los años 5047, los de A. Tanodi, R. H. Bautier, L. González, Y. Perotin, o J. Mazzoleni, y de otra forma L.M. Kane y el español A. Matilla Tascón en los años $60^{48}$ los de la Asociación de Archiveros

${ }^{47}$ BRENNEKE, A. Archivkunde. Ein Beitrag zur Theorie und Geschichte des europäischen Archivwesens, bearbeitet nach Vorlesungs-nachschriften und Nachlasspapieren und ergänzt von Wolfgang Leesch. Leipzig: Koehler e Amelag, 1953; PANELLA, A. Scritti archivistici, a cargo de Arnaldo d'Addario. Roma: Archivi di Stato, 1955; SCHELLENBERG, T. R. Modern Archives. Principles and Techniques. Chicago, London: University of Chicago, Midway reprint, 1975. (Hay una $1^{\text {a }}$ ed. Melboume, Adelaida, London, Wellington, 1956; y una 2 $2^{-}$ed., Chicago, 1957); ídem. Archivos modernos. principios y Técnicas. La Habana: Instituto Panamericano de Geografía e Historia, 1958; ídem. Manual de arquivos. Traduçao de Manoel A Wanderley. Rio de Janeiro: Arquivo Nacional, 1959; CICERI, A Archivi e archivistica. Milán: CETIM, 1959; y FAVIER J. Les archives. Paris: Presses Universitaires de France, 1985 (1 $\stackrel{\text { a }}{\text { ed. }}$ 1959; $3^{\underline{a}}$ ed, 1975).

${ }^{4}$ TANODI, A. Manual de archivología hispanoamericana: Teorías y principios. Córdoba (Argentina): Universidad Nacional, 1961. (Universidad Nacional de Córdoba. Facultad de Filosofía y Humanidades. Escuela de Archiveros. Collectánea Archivística, v. 1); BAUTIER, R. H. "Les archives". En: L "HITOIRE et ses méthodes. Paris: Gallimard, 1961, vol. 11, pp. 1120-1166; MAZZOLENI, J. Lezioni di Archivistica. Napoli: [L'Arte Tipografica], 1962; PEROTIN, Y. Manuel d'archivistique tropicale. Paris: Moulon et Co., 1966; GONZÁlEZ RAMÍREZ, L. Archivonomía. México: Eca, 1969;KANE, L. M. A Guide to the care and administration of manuscripts. Nashville: American Association for State and Local History, 1966 (2 ed.); MATILLA TASCON, A. Cartilla de organización de Archivos. MadridValencia: Tip. Moderna, 1960. 
franceses, G. Cencetti,S. H. Hodson, J. Mazzoleni, C. F. Eckart, E. G. Franz, K.W. Duckett, M. J. Brichford, S.E. Holbert, M. Cook, M. Pereira,V. Cortés Alonso,o el de H.A. Taylor y E. Taillemite en los años $70^{49}$, por no citar los numerosos de las últimas dos décadas ${ }^{50}$, entre los que hay un numero no pequeño de nuestro estado ${ }^{51}$.

\begin{abstract}
49 ASSOCIATION DES ARCHIVISTES FRANÇAIS. Paris. Manuel d'Archivistique, Théorie et practique des Archives publiques en France. Paris: Sevpen, Imp. National, 1970. (Reed. de 1991); CENCETTI, G. Scritti archivistici. Roma: Il Centro di Ricerca, 1970; HODSON, S.H. The Administration of archives. Oxford: pergamon Press, 1972; MAZZOLENI, J. Manuale di Archivistica. Napoli: Librería Scientifica, 1972; ECKHART, C.F. Ein führung in die archivkunde. Darmstadt: Wissenschaftliche Buchgesesllschaft, 1974; FRANZ, E.G. Einführung in die Archivkunde. Darmstadt: Wissenschaftliche Buchgesesllschaft, 1974; DUCKETT, K. W. Modern manuscripts: a practical manual for their management, care and use. Nashville: American Association for State and Local History, 1975; BRICHFORD, M.J. Archives e manuscripts. Appraisal e accessioning. Chicago: [SAA], 1977; HOLBERT, S. E. Archives e Manuscripts: Reference e Access. Chicago: SSA, 1977; COOK, M. Archives administration. A manual for intermediate and smaller organizations and for local government Folkestone Kent: Wm Dawson and Son, 1977; ídem. Archives. Paris: CIA, 1978. (Reprinted for the ICA from ALA world Encyclopedia of Library and Information Service, pp. 36-54); PEREIRA, M. Apontamentos de Arquivología e Arquivoeconomía. Coimbra, 1978; CORTÉS ALONSO, V. Archivos de España y América: Materiales para un manual. Madrid: Universidad Complutense, 1979; o TAYLOR, H.A.; TAILLEMITE, E. The arrangement and description of archival materials. With a contribution by E.Taillemite: les instruments de recherches dans les archivoes. Munich, 1979.

${ }^{50}$ Cronológicamente y de forma restrictiva: COUTURE, C.; ROUSSEAU, J.Y. Les archives au XXe siècle: une réponse aux besoins de l'administration et de la recherche. Montréal: Université de Montréal, 1982; PEDERSON, A. E.; CASTERLINE, G. F. Archives e Manuscripts: Public Programs (SAA Series II), 1982
\end{abstract}

BERNER, R.C. Archival theory and practice in the United States: a historical analysis. Seattle: University of Washington Press, 1983; LODOLINI, E. Archivística: Principi e problemi. Milano: Franco Angeli, 1984; TAYLOR, H. A. Archival services and the concept of the user. Paris: UNESCO, 1984; FELICE, R. de L'archivio moderno nella publica administrazione: Manuale per la organizzazione, tenuta e funzionamento degli archivi correnti e di deposito. Roma: Edizione dell'Anai, 1985; COOK, M. The Management of information from Archives. Aldershot: Gower, 1986; AUSTRALIAN SOCIETY OF ARCHIVISTS. Keeping archives. Sidney, 1987; CHAMPAGNE, M.; CHOUINARD, D. Le traitement d'un fonds d'archives: ses documents historiques. Montreal: Documentor, Université de Montréal, 1987; ALCÁNTARA, D. Manual de Arquivos Municipais. San Salvador de Bahia: Secretaria de Cultura e Turismo. Arquivo Público do Estado da Bahia, 1988; BAIRD, D.; COLES, L.M. A manual for small archives. Vancouver: Association of British Columbia Archivist, 1988; CARUCCI, P. Le fonti archivistiche: Ordinamento e conservazione. Roma: La Nuova Italia Scientifica, 1988; HEDSTROM, M. Archivos y Manuscritos: los documentos en soporte informático. Trad. de Adela Areces et al. Coblenza: Consejo Internacional de Archivos, Comité de Automatización, 1988; BEARMAN, D.A. Archival methods. Pittsburgh, PA: Archives e Museum Informatic, 1989; BRADSHER, J.G. Managing archives and archival institutions. Chicago: Unive. of Chicago, 1989; HIVES, C. (Ed.) Archival appraisal: Theory and practique. Vancouver. Association of British Columbia Archivist, 1990; PLESSI, G. Compendio di Archivistica. Bolonia: CLUEB, [1990]; BELlOTTO, H. L. Arquivos permanentes: Tratamento Documental. Sao Paulo: T.A. Queiroz, 1991;BLACK, E. Le controle d'autorité: un manuel destiné aux archivistes. Otawa: Comité de planification sur les normes de description, 1991; COX, RJ. Managing institutional archives. Foundation principles and practices. New York: Greenwood, 1992; DOLLAR, C.M. Archivistica e informatica: l'impatto delle tecnologie dell'informazione sui principio e sui metodi dell'archivistica. Macerata: Publicazioni dell'Università, 1992; DUCHEIN, M. Étude d'Archivistique, 1957-1992. Paris: Association
Por otro lado, la producción profesional encuentra un nuevo vehículo de expresión, el de las publicaciones periódicas que, por su propia naturaleza, ponen de relieve el ritmo que va adquiriendo el desarrollo archivístico, a punto de precisar un vehículo de expresión más rápido y renovable que el de las monografías. Así van surgiendo gran

des Archivistes Français, 1992;EASTWOOD, T. (Ed.) The Archival Fonds: from Theory to Practice. Ottawa: Bureau of Canadian Archivist, 1992; ROBERGE, M. La gestion de l'information administrative: aplication globale, systémique et systematique. [Quebec]: Documentator, 1992; COOK, M. Information management and archival data. London: Library Association Publishing, 1993; HEDSTROM, M (Ed.). En Electronic Records Management Program Strategies. Pittsburgh, PA: Archives and Museum Informatics, 1993; HILL, M. R. Archival strategies and techniques. Newbury Park [etc.]: SAGE Publications, 1993; ROBERGE, M. La gestión dels documents administratius. Barcelona: Diputació, Associació d'Arxivers de Catalunya, 1993; BEARMAN, D. Electronic evidence: strategies for managing records in contemporary Organizations. Pittsburgh: Archives and Museum Informatics, 1994;COUTURE, C.; ROUSSEAU, J.Y. Les fondements de la discipline archivistique. Québec: Presses de l'Université du Quebec, 1994; COX, R.J. The first generation of electronic records archivista in the United Stated. A study in professionalization. New York: Haworth Press, 1994;ESPOSEL, J. P. Arquivos: uma questao de ordem. Rio de Janeiro: Muiraquita, 1994;PENN, I.; MORDDEL, A.; PENNIX, G. y SMITH, K. Record Management handbook. Vermont: Gower, 1994; CHAUMIER, J. La gestion électronique des documents. Paris: Presses Universitaires de France, 1996;LÓPES, L. C. La información y los archivos: teorías y prácticas. s.l. Buenos Aires: Asociación Bonaerense de Archiveros (ABA), s.i.: 1996; CHABIN, M.A. Le management de l'archive. París: Hermes Science, 2000.

${ }^{51}$ Cronológicamente y sin ánimo de exhaustividad: CONTINOLO, G. El Archivo en la organización moderna. Bilbao, 1981; CORTÉS ALONSO, V. Manual de Archivos Municipales. Madrid: ANABAD, 1982;BIRAGHI, C. Técnicas modernas de Archivo. Manual práctico de organización y funcionamiento. Barcelona, 1984; GALLEGO DOMINGUEZ, O.; LÓPEZ GÓMEZ, P. Introducción na arquivística. Vigo: ANABAD, 1985. Reedición en castellano y euskera: Artxibistikan Sarrera = Introducción a la Archivística. Vitoria-Gasteiz: Eusko Jaurlaritzaren Argitalpen Zerbitzu Nagusia / Servicio Central de Publicaciones. Gobierno Vasco, 1989; PESCADOR DEL HOYO, M.C. El archivo. Instrumentos de trabajo. Madrid: Norma, 1986; HEREDIA BERRERA, A. Archivística general. Teoría y práctica Sevilla: Diputación Provincial, 1988; AGUINAGALDE, F. Archivo de familia: materiales para un manual. Vitoria-Gasteiz: Irargi, Centro de patrimonio Documental de Euskadi, 1991;ALBERCH, Ramón; BOADAS, Joan. La función cultural de los archivos. Bergara: Irargi, 1991;CONDE VILLAVERDE, M. L. Manual de tratamiento de archivos administrativos. Madrid: Ministerio de Cultura, 1992; GALLEGO DOMÍNGUEZ, O. Manual de organización de archivos familiares. Madrid: ANABAD, 1993; LLANSÓ, J. Gestión de documentos: definición y análisis de modelos. Bergara: Irargi. Centro de Patrimonio Documental de Euskadi, 1993; CARUCCI, P. et al. Documento y archivo de gestión: diplomática de ahora mismo. Carmona: S.C. Ediciones, Universidad Internacional Menéndez Pelayo, 1994; CAYETANO MARTÍN, C. et al. Los Archivos de la Administración Local. Toledo: ANABAD Castilla-La Mancha, 1994; CRUZ MUNDET, J. R. Manual de Archivística. Madrid: Fundación Germán Sánchez Ruipérez: Pirámide, 1994; FUSTER RUIZ, F. Política y planificación de Archivos. Murcia: D.M. Librero Editor, 1995; ROMERO TALLAFIGO, M. Archivística y archivos: soportes, edificios y organización. Carmona (Sevilla): SeC ediciones, 1995 (2ª ed.);RUÍZ RODRÍGUEZ, A. (Ed.) Manual de Archivística. Madrid: Síntesis, 1995; MOLINA NORTES, J.; LEYVA PALMA, V. Técnicas de archivo y tratamiento de la documentación administrativa. Guadalajara: ANABAD Castilla-La Mancha, 1996; TAMAYO, A. Archivística, Diplomática y Sigilografía. Madrid: Cátedra, 1996; CERDÁ DÍAZ, J. Los archivos municipales en la España Contemporánea. Gijón: TREA, 1997;DUPLÁ DEL MORAL, A. Manual de Archivos de Oficina para Gestores. Comunidad de Madrid: Madrid Comunidad de Madrid, Marcial Pons, Ediciones Jurídicas y Sociales, 1997; FERNÁNDEZ GIL, P. Manual de organización 
número de revistas prestigiosas: ${ }^{52} \mathrm{La}$ Gazette des Archives, The American Archivist, Der Archivar, Archivum, Archivio Storico Italiano, Rasegna degli Archivi di Stato, etc., y ya en España, Lligal, Tabula, Tria, Irargi, Bilduma, etc ${ }^{53}$.

Por otro lado, en los último años se ha producido un importante desarrollo normativo para el ámbito archivístico a

de archivos de gestión en las oficinas municipales. Granada: CEMCI, 1997; PÉREZ HERRERO, E. El Archivo y el Archivero. Sus técnicas y utilidad para el Patrimonio Documental Canario. s.l.: La Laguna: Viceconsejería de Cultura y Deportes, 1997; CRUZ MUNDET, J.R.; y MIKELARENA PEÑA, F. Información y Documentación Administrativa. Madrid: Tecnos, 1998; ALBERCH FUGUERAS, R.; CRUZ MUNDET, J.R. iArchívese! Los documentos del poder. El poder de los documentos. Madrid: Alianza Editorial, 1999;GARCÍA RUIPÉREZ, M.; FERNÁNDEZ HIDALGO, M. C. Los archivos municipales en España durante el Antiguo Régimen: Regulación, conservación, organización y difusión. Cuenca: Universidad de CastillaLa Mancha, 1999;NÚÑ̃EZ FERNÁNDEZ, E. Organización y gestión de archivos. Gijón: TREA, 1999; RUBIO MERINO, P. Archivística eclesiástica: nociones básicas. Sevilla: Guadalquivir, 1999; SANCHíS MORENO, F. Los archivos de oficina: una síntesis para su gestión. Valencia: Tirant lo Blanch, 1999; SASTRE SANTOS, E. Manual de archivos. El sistema archivístico diocesano: Archivos de la curia y archivos parroquiales. Madrid: ANABAD, 1999; ALBERCH FUGUERAS, R.; BOIX LLONCA, L.; NAVARRO SASTRE, N.; y VELA PALOMARES, J. Archivos y cultura. Manual de dinamización cultural. Gijón: TREA, 2001.

${ }^{52}$ Entre otras muchas: AMERICAN ARCHIVIST. THE. Society of American Archivist. Chicago (Illinois). Trimestral. 1938; GAZETTE DES ARCHIVES, LA. Paris: Association des archivistes Françaises. Trimestral. 1947; ARCHIVES. London: British Record Association. Semestral. 1949; ARCHIVUM. International Review on Archives=Revue internationale des Archives. Paris. Annual. 1951; ARCHIVAE ECLESIAE. Roma. Irregular. 1958-80; RASSEGNA DEGLI ARCHIVI DI STATO. Roma: Direccione Generale degli Archivio di Stato. Cuatrimestral. 1961; ARCHIVES. Quebec: Association des Archivistes du Quebec. Trimestral. 1969-1991; ARCHIVES ET BIBLIOTEQUES DE BELGIQUE. Bruxelles: Association des Archivistes et Bibliotecaires de Belgique. Semestral. 1971; ARCHIVES DE L'EGLISE DE FRANCE. Bulletin de l' Association des Archivistes de l'Eglise de France. Paris. 1974; ARCHIVISTE, L' = ARCHIVIST, THE. Ottawa: Archives Nationales du Canada. Bimestral. 1974; ARCHIVAR. Stuttgart, Trimestral. 1975; ARCHIVARIA. Ottawa: Association of Canadian Archives. Semestral. 1975; ARMA. Records Management Quaterly. Prairie Vilage. Trimestral. 1980;INTERNATIONAL JOURNAL OF ARCHIVES. New York. Semestral. 1980; JOURNAL OF THE SOCIETY OF ARCHIVISTS. London. Semestral. 1980;RECORDS MANAGEMENT QUARTERLY. Prarie Village: ARMA International. Trimestral. 1980;BUSINESS ARCHIVES. London. Annual. 1982; JANUS: Bulletin de la Section des Associations Profesionelles du Conseil International des Archives. Bois le Duc: CIA, SPA. Annual. 1983;BIBLIOTECAS, ARQUIVOS E MUSEUS. Lisboa. Semestral. 1985;ARCHIVES AND MANUSCRIPTS. The Journal of the Australian Society of Archivist. O'Connor. Semestral. 1986; ARCHIVIO STORICO ITALIANO. Firenze. 1989; BIBA. Boletim de Informaçao Bibliográfica en Arquivología. Rio de Janeiro. Anual. 1994.

53 Entre otras: BOLETÍN DE LA ANABAD (ASOCIACION ESPAÑOLA DE ARCHIVEROS, BIBLIOTECARIOS, MUSEOLOGOS Y DOCUMENTALISTAS), Madrid. Trimestral, 1950;DOCUMENTACIÓN DE LAS CIENCIAS DE LA INFORMACIÓN.Facultad de Ciencias de la Información. Universidad Complutense. Anual. Madrid, 1976; BILDUMA. Boletín del Archivo y Biblioteca Municipales de Rentería (Guipúzcoa), 1987; ANALES DE DOCUMENTACIÓN. Facultad de Documentación. Universidad de Murcia. Murcia, 1998;IRARGI. Revista de Archivística. Bergara: Centro del Patrimonio Documental de Euskadi. Bilbao. Anual. 1988; LLIGALL. Revista Catalana d'archivística. Barcelona: Associació d'Arxivers de Catalunya. Anual. 1988; CUADERNOS E.U.B.D. la luz de la Constitución de 1978 y el reparto de competencias entre el Estado y las Comunidades Autónomas. La Ley de Patrimonio Histórico Español ${ }^{54}$, las diferentes Leyes de Archivos y Patrimonio Histórico y Cultural de las Comunidades Autónomas ${ }^{55}$, el desarrollo normativo para los Archivos Municipales y la documentación administrativa ${ }^{56}$, las diferentes normas europeas ${ }^{57}$, o las nuevas y necesarias normativas para la documentación electrónica ${ }^{58}$ lo demuestran. En definitiva, a pesar de que quedan por perfilar diversas demandas (desarrollo de la Ley de Patrimonio, definición de un modelo autonómico de organización de archivos, precariedad normativa de determinadas cuestiones) lo cierto es que nos encontramos en una normalización más desarrollada y en proceso.

Complutense. Madrid. 1991. (Continuada por REVISTA GENERAL DE INFORMACIÓN Y DOCUMENTACIÓN. Editorial Complutense. 1992); TÁBULA. Revista de Archivos de Castilla y León. Salamanca: Asociación de Archiveros de Castilla y León. Anual. 1992;MÉTODOS DE INFORMACION (MEI). Valencia: Associació valenciana d'especialistes en informació. Bimestral. 1994; SIGNO. REVISTA DE HISTORIA DE LA CULTURA ESCRITA. Alcalá de Henares. Anual. 1994; TRIA. Sevilla: Asociación de Archiveros de Andalucía. 1994.

${ }^{54}$ Ley 16/1985, de 25 de junio, del Patrimonio Histórico Español; B.O.E. 155, 29 de junio de 1985, pp. 20.342-20.352.

${ }^{55}$ Por este orden: Andalucía (Ley 3/ 1984 de 3 de Enero, de Archivos. Ley 1/191, de 3 de julio, del Patrimonio Histórico Andaluz, que modifica y amplia la Ley anterior. Ley 37/1999, de 28 de abril, de modificación de la Ley 3/1984); Cataluña (Ley 6/1985, de 26 de abril, de Regulación de los Archivos de Cataluña. Ley 8/1989, de 5 de junio, de modificación de la Ley 6/185, de 26 de abril, de Archivos); Aragón (Ley 6/1986, de 28 de noviembre, de Archivos de Aragón); Canarias (Ley 3/990, de 22 de febrero, sobre normas reguladoras del Patrimonio documental y Archivos); Murcia (Ley 6/1990, de 11 de abril, de Archivos y Patrimonio Documental); Castilla-La Mancha (Ley 4/1990, de 30 de mayo. del Patrimonio Histórico de Castilla-La Mancha); Castilla y León (Ley 6/1991, de 19 de abril, de Archivos y Patrimonio Documental); Cominidad de Madrid (Ley 4/193, de 21 de abril, de Archivos y Patrimonio Documental. Ley 10/1998, de 9 de julio, del Patrimonio Histórico); La Rioja (Ley 4/1994, de 24 de mayo, de Archivos y Patrimonio Documental); Galicia (Ley de 1995, de 30 de octubre, del Patrimonio Histórico); Comunidad Valenciana (Ley de 1998, de 11 de junio, del Patrimonio Histórico Artístico); Cantabria (Ley 11/1998, de 13 de octubre, del Patrimonio Cultural); Islas Baleares (Ley 12/1998, de 21 de diciembre, del Patrimonio Histórico) y Extremadura (Ley 2/1999, de 29 de marzo, del Patrimonio Histórico y Cultural).

${ }^{56}$ Ley de Bases Reguladora del Régimen Local 7/1985 (B.O.E. 3 de abril de 1985, no 80). Arts. 18, 25, 70 y 77; Real Decreto 111/1986 de 10 de enero de desarrollo parcial de la Ley 16/1985 de Patrimonio Histórico Español (B.O.E: de 11 de mayo de 1989, no 112); Ley 12/1989 de 9 de mayo que regula la función estadística pública (B.O.E. de 11 de mayo de 1989 , nº 112); Ley Orgánica 5/1992 de Regulación de tratamiento automatizado de los datos de carácter personal (B.O.E. de 31 de octubre de 1992, nº 262); Ley 30/1992 de Régimen Jurídico de ls Administraciones Públicas y del Procedimiento Administrativo Común (B.O:E. de 27 de noviembre de 1992, no 285); Real Decreto 64/194 de 21 de enero que modifica parcialmente el Real Decreto 111/1986 de desarrollo parcial de la Ley 16/1985. (B.O.E. de 2 de marzo de 1994, № 2), Real Decreto Legislativo $1 / 196$ de 12 de abril por el que se aprueba el texto refundido de la Ley de Propiedad Intelectual, regularizando y armonizando las disposiciones legales vigentes sobre la materia (B.O.E. de 22 de abril de $196 \mathrm{n}^{\circ}$ 97); Real decreto $139 / 2000$ de 4 de febrero de 2000 , por el que se regula la composición, funcionamiento y competencias de la Comisión Superior Calificadora de Documentos Administrativos (B.O.E. de 11 de febrero de 200, no 36), etc. 


\section{El tiempo de la archivística - un estudio de sus espacios de racionalidad histórica}

En tercer lugar, la disciplina archivística se institucionaliza in ternacionalmente, desplazando de manera paulatina e irreversible las controversias nacionales. La normalización necesaria, la forzosa universalización de los principios teóricos, la homologación en la terminología, o el consenso en cuestiones tan dificultosas como los contenidos de la formación profesional han resultado ser elementos de trascendental importancia a efectos de creación de organismos internacionales en materia archivística. Evidentemente el órgano clave será el Consejo Internacional de Archivos (CIA), que desenvolverá una planificación y política archivística universal con diferentes secciones, grupos de trabajo, comités y múltiples órganos de expresión. ${ }^{59}$

Por otro lado, prueba del desarrollo de los Archivos en este período es el aumento del asociacionismo profesional. En este sentido, es unánime la opinión que asevera que las Asociaciones Profesionales, en su constante devenir y fortalecimiento, han impulsado activamente determinados aspectos de la disciplina, aportando seguridades internas, y ayudando a mantener, yo diría que de forma extraordinariamente competente, los equilibrios necesarios para la formación, complementando así a la enseñanza académica. Igualmente, es interesante observar cómo durante las últimas dos décadas han proliferado el número de asociaciones y grupos de trabajo que han desarrollado,

\footnotetext{
${ }^{57}$ Entre otras: Reglamento CEE 3911/92 del Consejo, de 9 de diciembre de 1992, relativo a la exportación de bienes culturales (DOCE de 31 de diciembre de 1992, no L 395/I,); Reglamento CEE 752/93 de la Comisión, de 30 de marzo de 1993, relativo a las disposiciones del Reglamento CEE 3911/92 del Consejo de 9 de diciembre de 1992, relativo a la exportación de bienes culturales (DOCE de 31 de marzo de 1993 n L 77); Directriz 93/7 CEE del Consejo, de 15 de marzo de 1993, relativa a la restitución de bienes culturales que han salido de manera ilegal del territorio de un Estado miembro (DOCE de 27 de marzo de 193, № L 74); Directriz 94/5 CEE del Consejo, de 14 de febrero de 1994, por la cual se modifica la Directriz 77/388 CEE de Régimen especial aplicable a los bienes de ocasión, objetos de arte, antigüedades y objetos de colecciones y fondos (DOCE de 3 de marzo de 1994, no L60/16); o Directriz del Parlamento Europeo 95/46 CEE de 24 de octubre relativa a la protección de las personas físicas respecto al tratamiento de datos personales (DOCE, de 30 de abril de 1995, nº L32/15), etc.

${ }^{58}$ Entre otras: Ley 30/1992, de 26 de noviembre, de Régimen Jurídico de las Administraciones Públicas y del Procedimiento Administrativo Común, art. 45; Acuerdo el Consejo de Ministros de 4 de abril de 1996, para la progresiva implantación de un sistema intercomunicado de registros entre la Administración General del Estado, las Administraciones de las Comunidades Autónomas y lsa Entidades que integran la Administración Local (B.O.E. de 14 de abril de 1999, no 89); Real Decreto-Ley 14/1999, de 17 de septiembre, sobre firma electrónica. (B.O.E., no 224), etc.

${ }^{59}$ Vid.: FRANZ ECKHART, G. "El CIA: sus logros y su futuro". En: IX Congreso Internacional de Archivos, Londres, 1980, pp. 1-33; EVANS, F.B. "The Action by UNESCO and CIA since 1976 ". En: 29-31ํ Conferencia Internacional de la Mesa Redonda de Archivos. Interdependence of Archives (...). París:ICA, 1998, pp. 69-78; KECSKEMETI, Charles. Activites of UNESCO and CIA since 1976. En: 29-31ํㅡㄹ Conferencia Internacional de la Mesa Redonda de Archivos. Interdependence of Archives (...) .París:ICA, 1998, pp.79-85, etc.
}

algunos de ellos con enorme eficacia, revistas específicas, colecciones monográficas, boletines y hojas informativas que han provocado, a la par que un despliegue teórico y técnico, un descentramiento fructífero, fenoménico y repleto de perspectivas. En consecuencia, las asociaciones profesionales han vigorizado los principios conceptuales mediante el fortalecimiento práctico y el aperturismo metodológico. ${ }^{60}$

Por último, no es menos sustancial un importante hecho: el reconocimiento oficial de la Archivística en la Universidad española, de mano, fundamentalmente, de las Facultades de Biblioteconomía y Documentación. ${ }^{61}$ Ello supone, a pesar de todas las deficiencias provocadas, por la escasez de asignaturas al respecto - y el tema recurrente de la formación -, un extraordinario acontecimiento para el desarrollo teórico y profesional de la disciplina archivística. Esta nueva situación, no cabe duda que constata los procesos de renovación teórica y empírica por los que la disciplina cruza. A mi entender, la universidad debe ser el punto de encuentro que considere la formación y la nueva actitud profesional desde premisas interdisciplinares, inserta en la visión teórica de la archivística que avala la integración, fomentando una formación armonizadora, abogando por una enseñanza equilibrada y desarrollando respuestas aplicables al impacto que supone la tecnología en la sociedad de la información. ${ }^{62}$

Evidentemente todas estas modificaciones, motivadas en gran medida en el propio desenvolvimiento de la disciplina, origina modificaciones sustanciales en los quehaceres del trabajo, y, en consecuencia, en las necesidades informativas. Ello ha supuesto que surjan nuevos temas de interés teórico y metodológico, donde la tecnología de la información, el régimen jurídico de la documentación o la normalización tienen un interés creciente en los últimos años.

En definitiva, en las ultimas décadas, a través del creciente progreso historiográfico, del importante desarrollo

\footnotetext{
${ }^{60}$ Son numerosas las Asociaciones Profesionales, unas de forma específica, y otras anexionados a documentalistas y bibliotecarios. Por ejemplo, para España:
}

Asociación de Archiveros de Andalucía, Asociació d'Arxivers de Catalunya, ANABAD, ALDEE, ACAL, etc. Otras relevantes son: American Society for Information Science, Australian Society of Archivist, The Society of American Archivist,etc.

${ }^{61}$ Antes son mencionables: La Escuela de Bibliotecarias de Barcelona, que creada en 1915, adquiere rango de universitaria en 1981; la Escuela de Bibliotecarias ubicada en la Universidad de Navarra en 1967 y desaparecida en 1977, que contaba con una asignatura denominada Archivonomía y Paleografía; el Departamento de Documentación de la Facultad de Ciencias de la Información de la Universidad Complutense de Madrid que, desde 1975, imparte asignaturas vinculadas; al margen, asignaturas de Archivística en diversos planes de Historia, el Departamento de Documentación de la Universidad Autónoma de Madrid, las cátedras de Historia de la Medicina, etc. 
normativo, del despliegue de la política archivística internacional, del aumento del asociacionismo profesional, y del reconocimiento armonizado de la archivística en la universidad española, se infiere que estamos asistiendo a un desarrollo teórico y a una expansión científica de la Archivística.

3a- La Archivística en el ámbito de las Ciencias de la Información y Documentación. Es evidente que el archivero, el bibliotecario y el documentalista tienen su propia finalidad y método, pero opinamos, tal y como lo hace M. Duchein, que la oposición tradicional entre ellos va diluyéndose de manera paulatina con el paso del tiempo. ${ }^{63}$

En este orden, todo parece indicar que al margen de las peculiaridades específicas, que las hay, y en ocasiones de gran consistencia teórica, de las nuevas propiedades documentales se infieren métodos de trabajo que exigen una mayor complementariedad. No debemos ignorar algo que, aunque se estime como algo axiomático, debe tener una consideración extraordinaria: la metodología de todos se engloba en el denominado proceso informativo-documental

${ }^{62}$ Cfr. ABADAL, E. y MIRALPEIX, C. "Los estudios de Biblioteconomía y Documentación en la Universidad española a finales de los noventa". BID: Textos Universitarios de Biblioteconomia i Documentació. 1999, 2. (U.R.L. http://www.ub.es/biblio/bid/02abamir.htm (Consulta realizada en febrero de 2001); COOK, M. Guidelines for currículum development in records management and the administration of modern archives: a RAMP study. París: UNESCO, 1982;COUTURE, C. "La formation en archivistique. Évolution, contexte et contenu". En International Council on Archives. Proffesional training of archivist. München [etc]: K.G. Saur, 1988, pp. 17-33. (Archivum, v. 34);FISHBEIN, M. A model curriculum for the education ad training of archivist in automation: a RAMP study. París: UNESCO, 1985; McCRANK, L.J. "Prospects for integrating historial and information studies in archival education". American Archivist. 1979, 42, 2, pp. 443. 455; COOK, T. "From information t knowledge. An intelectual paradigma for archives". Archivaria. 1985, 25, 1, pp. 28-49; MENNE-HARITZ, A. "Archivfachliche ausbildung: den anforderungen der gesellschaft des 21 jahrhunderst gerechtwerden”. En International Council on Archives. 12th. International Congress on Archives (Montreal, December 1992). München [etc]: K.G. Saur, 1994, pp.261-284. (Archivum, v. 39); SAUNDERS, W.L. Directrices para el desarrollo de programas de estudios de ciencias de la información. París: UNESCO, 1978; UNESCO. Meeting of experts on the harmonization of education and training programmes, 26-30 Nov. 1979: Final report. París: UNESCO, 1980; UNESCO. Meeting of experts on the harmonization of education and training programmes in information science, librarianship and archives. París: UNESCO, 1984, etc. (Nos basamos en el Véanse, al respecto, los brillantes trabajos de Eduardo Peis, profesor de Archivística de la Universidad de Granada, algunos de ellos inéditos. En ellos nos basamos en algunos puntos. Agradecemos de forma sincera su apreciable ayuda. (Nos basamos en su Proyecto docente titulado: Tratamiento técnico del documento primario. Para este punto, vid. 1.2.2.1.2. El ciclo de vida de los documentos, pp. 108-113).(Cit.por PEIS REDONDO, E. Tratamiento técnico del documento primario. Proyecto docente. Agradecemos de forma sincera su apreciable ayuda).

${ }^{63}$ DUCHEIN, M. "El archivero en la era de la comunicación: especificidad y expansión de la archivística”. Irargi. Revista de Archivística. 1989, II, pp. 9-35.

${ }^{64}$ LÓPEZ YEPES, J. Teoría de la Documentación. Pamplona: EUNSA, 1978, pp.1-6 y $11-28$. inmerso en el contexto de las Ciencias de la Información determinando la Archivística como disciplina que no debe quedar al margen de la caracterización de la Documentación como ciencia para la ciencia y como ciencia informativa. ${ }^{64} \mathrm{La}$ Archivística, pues, como parte de un criterio pluralista de la Documentación que da lugar a un concepto sincrético e integrador de ésta ${ }^{65}$.

Entiendo, en consecuencia, una enseñanza de la Archivística integrada en el ámbito de las Ciencias de la Documentación, como preconizan las instituciones internacionales de archivo (CIA), sin que ello impida especializaciones propias de las especificidades. ${ }^{66}$

Podríamos establecer, aunque de forma telegráfica, algunas similitudes, puntos de encuentro, áreas comunes, retos similares, que aconsejan la confluencia y la colaboración entre las Ciencias de la Documentación, partiendo de la base de que los objetivos son por un lado, conservar la información y hacerla disponible a los que la necesitan, y, por otro, facilitar el acceso al conocimiento de los documentos y a su contenido. ${ }^{67}$ :

1. La gestión de los documentos. Es imprescindible perfeccionar la circulación, divulgación y acceso a la información, conformando la gestión documental hacia las crecientes demandas informativas.

2. Las nuevas tecnologías. El impacto tecnológico está generando en los sistemas de gestión de archivos inusitados contornos teórico. De manera que se plantean como necesidad novedades conjuntas en el tratamiento metodológico, por ejemplo, de los nuevos documentos electrónicos.

3. Los lenguajes documentales. En este orden de cosas, pensamos con Valle Gastaminza que una de las principales aportaciones que la Documentación puede hacer a la Archivística proviene de su "propia consideración como disciplina lingüístico-informativa y está en los métodos de análisis de contenido de los documentos y, sobre todo, en el uso de lenguajes documentales apropiados para la indización y recuperación documental." 68

\footnotetext{
${ }^{65}$ Ibídem, p. 50.

${ }^{66}$ MARTÍN FUERTES, J.A. "La enseñanza de la Archivística". En MARTÍNEZ COMECHE, J. A (Coord..) Métodos didácticos en Biblioteconomía y Documentación. VI Jornadas Académicas organizadas por la Escuela Universitaria de Biblioteconomía y Documentación de la Universidad Complutense de Madrid. Madrid, 1997, p. 237.

${ }^{67} \mathrm{DUCHEN}, \mathrm{M}$. "El archivero en la era de la comunicación: especificidad y expansión de la archivística”. Irargi. Revista de Archivística. Op. Cit., p. 32. ${ }^{68}$ DEL VALLE GASTAMINZA, F. "La aportación de la Documentación a la descripción en un medio de Archivos". Irargi. Revista de Archivística.1991, IV, pp. 107-117.
} 
El tiempo de la archivística - un estudio de sus espacios de racionalidad histórica

4. Formación integrada y armónica: Contemplamos, ya lo hemos dicho, como objetivo la instrucción de futuros gestores de la información, conditio sine qua non para el acrecentamiento de la productividad y la difusión del conocimiento. Entiéndasenos: armonización no es uniformidad, sino bases paritarias y diversificación de las especificidades.

5. La función informativa: Entendemos que es un factor socio-cultural clave para entender el despliegue de la Archivística: función jurídica, garantía de derechos y memoria histórica, se unifican por antecedentes en función informativa. En definitiva, la salvaguarda de la información, su disposición, y ella obtención del mensaje documentario como sustento metodológico. ${ }^{69}$

4⿳亠口冋. Archivos como Sistemas de Información. Durante este período la Archivística amplía sus dominios al tiempo que se contextualiza. Es el momento en el que la disciplina sufre una especie de "crisis de la conciencia" ante el problema ocasionado por la producción extraordinaria de documentos. En consecuencia, administraciones públicas, que multiplican sus estructuras y despliegan las prácticas documentales, y empresas privadas demandan, cada vez con mayor impetuosidad, un empirismo pragmático y una acentuación del carácter técnico en el tratamiento documental. La archivística resulta estar impulsada a inmiscuirse en la documentación administrativa y en la gestión de los documentos.

Esta expansión, por tanto, se traduce ineludiblemente en una intervención global de la documentación administrativa. La posible polémica no merece tener aquí mayor trascendencia. Glosada de forma solícita, entendemos por ésta la parte de las Ciencias de la Documentación que tiene por objeto de estudio el documento administrativo -como conjunto de publicaciones formales e informales cuya fuente es la Administración pública y privada- y su proceso documental, fundamentado en la generación, tratamiento, recuperación y difusión de mensajes documentarios objetivados en la práctica de la administración, para ser utilizado por el usuario con objeto de que puedan servir de base en el proceso de toma de decisiones o para la obtención de nuevo conocimiento. El concepto se aplica, de forma progresiva, a una Disciplina especializada que la contextualiza culturalmente. Se trata de la relativa a la enseñanza de las características del sistema de información en la Administración y de los subsistemas que lo componen, con objeto de estudiar

\footnotetext{
${ }^{69}$ Vid. Infra Cap. 4.6. "La función informativa". (Cfr. como síntesis CRUZ MUNDET, J.R "LA Archivística su espacio en las Ciencias de la Documentación”. En Manual... Op. Cit., pp. 55-77).
}

los procesos de generación, tratamiento, recuperación y difusión de la información objetivada en la práctica de la Administración Pública. ${ }^{70}$

No obstante, conviene que descendamos en los planteamientos hacia ámbitos más específicos dada la multiplicidad de perspectivas. Así, distinguiremos como objeto de estudio la documentación administrativa interna, dado que se configura como nuestro habitual espacio de aplicación, máxime si su diversificación se origina en la etapa que analizamos. Entiendo por ésta la parte de la Documentación Administrativa que considera el documento producido naturalmente por la propia administración en el ejercicio de sus funciones, actividades, procedimientos y trámites administrativos, esto es, la información administrativa de la Administración. ${ }^{71}$

Pero, si se nos permite, precisemos aún más dado que, como decimos, es la gestión documental la labor que se le reclama a la nueva archivística. Ciertamente, el sintagma gestión de documentos deviene con ambigüedad y, dependiendo de escuelas y autores, podría encubrir diversidad de significados. Nosotros lo interpretamos como el conjunto de operaciones y técnicas de la gestión administrativa general que se ocupa de los documentos durante su creación, mantenimiento, utilización y disposición final, que tiene por objeto conseguir la eficiencia y la economía de los archivos mediante la simplificación de creación documental, la mejora de los sub-sistemas de clasificación, conservación y eliminación, y descripción y recuperación con el propósito final de conseguir una eficaz gestión de la información. ${ }^{72}$

70 Vid. LÓPEZ YEPES, J. Teoría de la documentación. Pamplona: Eunsa, 1978; LÓPEZ YEPES, J. y ROS GARCÍA, J ¿Qué es documentación? Teoría e historia del concepto en España. Madrid. Síntesis, 1993, p. 141; o MOREIRO GONZÁLEZ, J. A.. Introducción bibliográfica y documental al estudio evolutivo de la Documentación. Barcelona: Publicaciones y Promociones Universitarias, 1990, pp. 307-308.

${ }^{71}$ Una buena síntesis sobre este punto la hacen Cruz Mundet y Mikelarena Peña:OTLET, P. Manuel de documentation administrative. Bruxelles: Institut International de Bibliographie, 1923, pp. 350-355 y 411-413; BADILLO NIETO, M. Y AZNAR PEÑARROYA, S. Técnicas de documentación para la Administración Pública. Madrid: Instituto Nacional de Administración Pública, 1986; PELOU, P. La documentation administrative. Paris: La documentation Française, 1988, p. 10; VELTEN, D "Les différents médias de la documentation administrative". En: PELOU, P. (Dir). La documentation administrative... Op. Cit., pp.. 58-76; ROBERGE, Michel. La gestion de l'information administrative: application globale, systemátique et sistemique. Quebec: Documentor 1992; ídem. La gestion des document administratifs. La Pocatière: Documentor, 1983; FERNÁNDEZ BAJÓN, M.T. "Documentación administrativa: una revisión de las tipologías documentales administrativas comunes”. Revista General de Información y Documentación. 1996, 6, 2, pp. 67-90, etc. (Cit. por CRUZ MUNDET, J. R. y MIKELARENA PEÑA, F. Información y Documentación Administrativa. Madrid: Tecnos, 1998, pp. 13-27). 
En definitiva, lo que se pretende es la creación de un sistema de gestión de la información administrativa como elemento constituyente de la gestión integral de la calidad en una organización. ${ }^{73}$

Así pues, entra en juego el concepto de "Calidad Total" o "Gestión integral de la Calidad", lo cual constata de forma clara y diáfana de qué forma los cimientos empresariales participan con nuevos recursos y procedimientos: en este caso, el derecho de los ciudadanos a recibir calidad en los servicios administrativos y documentales al coste más bajo posible ${ }^{74}$. Ello se traduce, al decir de los estudios iniciáticos, en un doble objeto: por un lado, la eficacia administrativa -acceder a la información en el instante preciso-y por otro, la rentabilidad administrativa -con los mínimos gastos- ${ }^{75}$

De todo ello, resulta una función claramente determinada: la inserción del archivo en la toma de decisiones, garantizando a todos los niveles la disposición y diligencia de la información necesaria en el momento oportuno. En este sentido, se hace imprescindible la regularización de los documentos administrativos, dado que su identificación y organización resultan ser básicos para el sustento de las decisiones. El archivo, pues, como componente de la secuencia: acceso a la información-toma de decisionesejecución de las mismas.

72 Según el Dictionnary of Archival Terminology la gestión de documentos es: "el área de gestión administrativa general relativa a conseguir economía y eficacia en la creación, mantenimiento, uso y disposición de los documentos" (ICA. Dictionary...Op. Cit., p. 76); la UNESCO, mediante el Programa RAMP (Record and Archives Management Programme), definía en 1979 gestión de documentos como:

"el dominio de la gestión administrativa general con vistas a asegurar la economía y al eficacia de las operaciones desde la creación, mantenimiento y utilización, hasta la afectación final de los documentos". (UNESCO. Consultation d'experts en vue de l'etablissement d'un programe a long terme en matière de gestion des documents et des archives (RAMP) dans le cadre du Programme General d'Information. 14-16 mai. Raport final. París: UNESCO, 1979, p. 79); más tarde, Eric Ketelaar, en 1985 lo define como la: "esfera de la gestión administrativa general que se ocupa de la eficiencia y la economía de los archivos en la creación, preservación, uso y depuración de los documentos, es decir, a lo largo de todo su ciclo de vida" (KETELAAR, E. Archival and records management legislation and regulations: a RAMP study with guidelines. París: UNESCO, 1985, p. 22. Cit. PEIS REDONDO, Op. Cit.).

${ }^{73}$ En este sentido es innegable el trabajo de M. Roberge y su grupo de investigación "Solutions Documentaires GESTAR". (Cfr."Le systeme de classification des documents administratifs". Lligall. 1990, 2, pp. 11-20; "La concepció, el desenvolupament i l'aplicació d'un sistema corporatiu i integrat de gestió automatitzada dels documents administratius". Lligall. 1991, 4 ,pàgs. 25-33; La gestion de l'information administrative. Application globale, systénique et systematique. La pocatiere: Documentator, 1992; y La classification universelle des documents administrative. La pocatiere: Documentator, 1985).

${ }^{74}$ Cfr. ROBERGE, M. "La gestión de calidad de los archivos". Tabula. 1994, no 3, pp. 105-123.

${ }^{75} \mathrm{Cfr}$. URANGA COGOLlOS, C. "El principio de eficacia en la organización administrativa. Hacia una Administración por sistemas". Documentación Administrativa. 1989, nº 218-219, pp. 97-109.
Llegados a este punto, es de vital importancia la consideración de la gestión de la información administrativa bajo la perspectiva de la teoría de los sistemas ${ }^{76}$ : "todo sistema es un subsistema de un sistema más amplio, y todo sistema está necesariamente compuesto de subsistemas".77 Así, los subsistemas de clasificación, de conservación y eliminación, y de descripción y recuperación de documentos son el sustento sobre los que elaboraremos el cuadro de clasificación, el calendario de conservación y eliminación, y el inventario y la síntesis descriptiva respectivamente. Estos productos, que se comportan de forma dialéctica, conseguirán el acomodo pragmático y el equilibrio imprescindible para la gestión de la información administrativa.

Ciertamente los conciertos no se imponen de inmediato, máxime si se trata de modificar mediante un sistema moderno al ya existente. Las inconveniencias son numerosas y las reticencias esforzadas. Con todo, la Archivística, en su desenvolvimiento hacia la gestión documental administrativa, consigue, junto al mantenimiento de los equilibrios, eficacia, fiabilidad y rentabilidad en las organizaciones. En otras palabras, nuestra disciplina presenta una valiosa voluntad de inserción en el ordenamiento de la toma de decisiones esenciales. ${ }^{78}$

5‥ El imperativo tecnológico ${ }^{79}$. Uno de las atributos de los últimos tiempos, y que de forma sistemática aparece ya como tópico historiográfico, es el que contempla el impacto que las tecnologías de la información están suponiendo en los sistemas de gestión de archivos y sus diferentes ámbitos.

${ }^{7}$ Véase para unas nociones preliminares: IUSSATO, B. Les structures de l'entreprise... París: Les editions d'Organisation, 1990; VINCENT, C.P. Des systèmes et des Hommes. Pour une nouvelle aproche du management. París: Les editions d'Organisation, 1990. Para la Administración Pública, vid. PARAMES MONTENEGRO, C. Introducción al management. Un nuevo enfoque de la Administración Pública. Madrid, 1974.

${ }^{77}$ Cfr. ROBERGE, M. "La gestión de calidad de los archivos". Tabula. 1994, no 3, pp. 105-123.

${ }^{78} \mathrm{Ibídem}$.

${ }^{79}$ Expresión de DOLLAR, C.M. Archivística e Informática: L'Impatto delle Tecnologie dell' informazione sui principio e sui metodi dell'Archivistica. Macerata: Publicazioni dell'Università, 1992, p. 37. Por su parte, M. Hedstrom habla de "tecnología condicionada y condicionante" ("Understanding electronic incunabula: a framework for research on electronic records". American Archivist. 1991, 54, 3, pp. 334-354), D.A. Bearman de "revolución de la información electrónica" ("Diplomatics, weberian bureaucracy, and the managment of electronic records in Europe and America" en American Archivist, 1992, 55, 1 Op. Cit., pp.168-181) y R. J. Cox lo denomina "determinismo tecnológico" (COX, R.J. The first generation of electronic records archivista in the United Stated. A study in professionalization. New York: Haworth Press, 1994, p. 9). (Basado en PEIS, E. Tratamiento técnico... Op. Cit.).

${ }^{80}$ Vid. al respecto: LÓPEZ YEPES, J. "Cambio social y política de Información y Documentación en España" en Revista de Documentación de las Ciencias de la Información, Madrid: Univ. Complutense, 1995, pp. 263-283; o una visión histórica en WHITE, L. Tecnología medieval y cambio social. Buenos Aires: Paidos Estudio, 1973. 
El tiempo de la archivística - un estudio de sus espacios de racionalidad histórica

Si la tecnología es una de las principales causas que históricamente han supuesto cambios sociales ${ }^{80}$, también lo es en nuestro contexto intelectual, profesional y funcional. En consecuencia, es el momento en que sobrevienen nuevos formatos, surgen inéditas posibilidades en los métodos, aparecen incertidumbres aplicativas, se origina expectación en las innovaciones..., en definitiva, se posibilitan mejoras en la coordinación y gestión de documentos a la par que un admitido desconcierto en su acomodación.

Lo que a todas luces resulta necesario es que, con estas importantes modificaciones, surja un novedoso marco teórico que tenga por objeto el tratamiento metodológico de los nuevos archivos y documentos electrónicos. Ello trae consigo variaciones en los métodos de trabajo, modificaciones de las prácticas y de los principios teóricos acostumbrados, y recientes estrategias para el tratamiento y la gestión de los originales documentos electrónicos a través de los Metadatos y sus diferentes aplicaciones. ${ }^{81}$

Frente al documento tradicional, el electrónico es "manipulable, enlazable interna y externamente, rápidamente transformable, intrínsecamente localizable, instantáneamente transportable e infinitamente replicable". ${ }^{82}$ De manera que el nuevo panorama se torna impreciso dado su espectacular despliegue, produciendo en su constante devenir transformaciones a diferentes niveles, reinterpretación de los principios asumidos, inseguridades múltiples asentadas en las resbaladizas estructuras metodológicas y comportamientos polarizados en los usos y modos.

Ciertamente no es éste un debate nuevo. Cada avance tecnológico que se ha producido en la historia ha implicado, de una u otra forma, en unos ,cierta vacilación que se traduce en perplejidad, y en otros, adaptación, ocasionándose, eso sí, radicales modificaciones en los métodos de trabajo. ${ }^{83} \mathrm{La}$ instantaneidad frente a la secuencia ordenada, la descentralización organizativa frente a la centralización, la transmisión horizontal de información frente a la estructura jerárquica, etc. son nuevos factores que refuerzan los cambios exigidos. En

\footnotetext{
$\overline{{ }^{81} \mathrm{Cfr} \text {. PEIS, E. "Archivos y el ciberespacio: aplicaciones a la institución }}$ universitaria". En VIVAS MORENO, A. (Ed.) Universidades y Archivos Universitarios: Historia y organización. Badajoz: Universidad de Extremadura; Centro de Historia Universitaria Alfonso IX. Universidad de Salamanca, 2001, pp. 159-190.

${ }^{82}$ Cfr. SCHAMBER, L. "What is a document? Rethinking the concepto in uneasy times". Journal of the American Society for Information Science, vol. 47, no 9, p. 669 (Cit. por PEIS, E. "Archivos y el ciberespacio..." Op. Cit., p. 163).Otros muchos autores han estudiado el tema. Por ejemplo, en España es interesante el artículo de Lluís-Esteve Casellsa i Serra en Lligall "Archivística y nuevas tecnologías: consideraciones sobre terminología, conceptos y profesión" que al hablar del documento electrónico afirma que es dinámico, multiforme, tipológicamente 'borroso' y compartido, y diplomáticamente contradictorio.(Ibídem)
}

otras palabras, la evolución no se produce sin sobresaltos teóricos. $^{84}$

La defensa de la procedencia como corpus teórico en torno al cual se pliega el desarrollo de la teoría archivística, el asequible acceso a la información contenida, o la valoración y selección de los documentos incluidos en las diferentes aplicaciones son algunos de los elementos que, al decir de algunos teóricos, pueden verse modificados. En este orden de cosas, se habla de "nuevo paradigma para los registros electrónicos", de la necesidad de plantear "una estrategia" al respecto, basada en los fines y no en los métodos, donde la intervención en el proceso de creación de los documentos resulte ineludible. ${ }^{85}$

Los metadatos resultan ser, en este sentido, un patrón eficiente para gestionar registros electrónicos, facilitando la identificación, localización, recuperación, manipulación y uso de objetos digitalizados en el entorno de redes electrónicas. ${ }^{86}$.

\section{CONCLUSIONES}

Durante este escueto recorrido se constata cómo paulatinamente se asiste al proceso de construcción de un campo de saber científico propio y específico, basado en dos ejes de evolución:

- Por un lado, el paso del pragmatismo al conocimiento científico del fenómeno archivístico, esto es, de práctica a ciencia, donde el lenguaje propio, la problemática construida, y los principios científicos originales han resultado ser componentes imprescindibles para la construcción de un saber archivístico que se consolida paulatinamente.

- Por otro, la pausada incorporación de la archivística a los procesos informativo-documental, con tres posibles

${ }^{83}$ Los registros electrónicos no son, como lo eran los tradicionales, elementos físicos, la información contenida en los documentos - hasta ahora unida al soporte - se determina como sustancialmente modificada, los puntos de la información resultan múltiples y las consultas no permanecen subyugadas al documento primario. En consecuencia, esta diversidad de perspectivas replantea los principios teóricos de la profesión. (Vid. COOK, Terry: "Interacción entre la teoría y la práctica archivística desde la publicación del manual holandés, en 1898" en Actas del Congreso del CIA en Pekín, p.17. Cit. CRUZ MUNDET, J.R. "La Gestión de Documentos en el Estado Español: Balance y perspectivas" en Métodos de Información no 17-18. (http://www.uv.es/cde/mei/mei17/pag28.html).

${ }^{84}$ Vid. PEIS REDONDO, E. "Archivos y el ciberespacio..." Op. Cit., pp. $164-165$.

85 "Una posible estrategia consiste en modificar el centro de atención desde el contenido de un registro a su contexto; desde el registro en sí mismo a la función de dicho registro; desde la preservación y acceso hacia la intervención en el proceso de creación" (Ibídem, p. 186).

${ }^{86}$ Ibídem 
etapas: una de dependencia teórica, una segunda de multidisciplinariedad, y una tercera de síntesis interdisciplinar pluralista.

En definitiva, la evolución de la Archivística transcurre:

a) De disciplina empírica y práctica a teoría científica que ha delimitado su problemática. Ésta estaría compuesta por los siguientes elementos: el paso de la oralidad a los instrumentos de comunicación materiales, la evolución de las formas jurídicas, el desarrollo de estructuras políticas centralizadas, la apropiación de la escritura y sus derivados, los sistemas de almacenaje y el uso de los testimonios escritos b) De limitada acción a una ampliación del campo de la actuación. No se trata de privilegiar ninguna aproximación sectorial sino secundar una postura armonizadora, que entiende que el archivero interviene sobre una cadena documental continuada.

c) De función coercitiva a necesidad informativa. Los archivos ya no se circunscriben a unos círculos eruditos más o menos minoritarios, sino que han entrado en el universo de lo social, lo cotidiano y lo cultural en sentido amplio.

Artigo recebido em 25-01-2005 e aceito para publicação em 29-03-2005. 